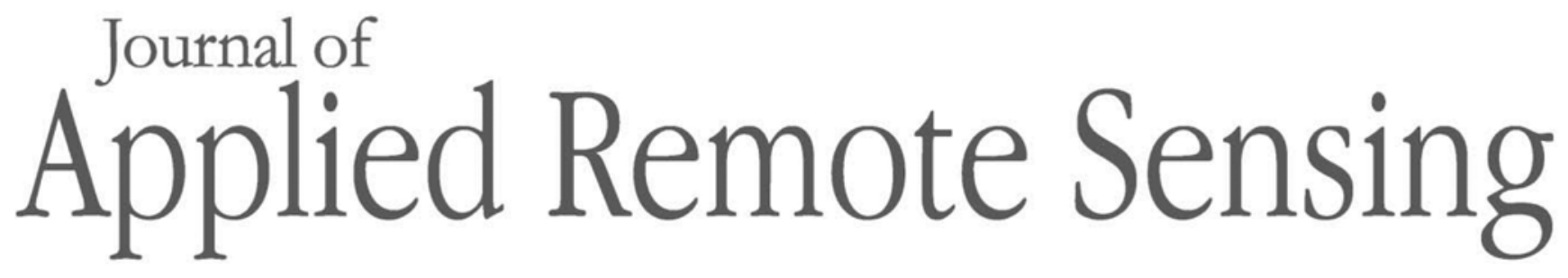

RemoteSensing.SPIEDigitalLibrary.org

\title{
Assessment of land subsidence using interferometric synthetic aperture radar time series analysis and artificial neural network in a geospatial information system: case study of Rafsanjan Plain
}

Mohsen Bagheri

Maryam Dehghani

Ali Esmaeily

Vahid Akbari 


\title{
Assessment of land subsidence using interferometric synthetic aperture radar time series analysis and artificial neural network in a geospatial information system: case study of Rafsanjan Plain
}

\author{
Mohsen Bagheri, ${ }^{a}, *$ Maryam Dehghani, ${ }^{\text {b }}$ Ali Esmaeily, ${ }^{a}$ and Vahid Akbaric \\ ${ }^{a}$ Graduate University of Advanced Technology, Department of GIS and Remote Sensing \\ Engineering, Kerman, Iran \\ ${ }^{\mathrm{b}}$ Shiraz University, School of Engineering, Department of Civil and Environmental Engineering, \\ Shiraz, Iran \\ ${ }^{c}$ University of Troms $\varnothing$, Department of Physics and Technology, Tromsø, Norway
}

\begin{abstract}
Land subsidence resulting from groundwater extraction is a widely recurring phenomenon worldwide. To assess land subsidence, traditional methods such as numerical and finite element methods have limitations due to the complex interactions between the different constructor factors of aquifer in each area. We produced a groundwater-induced subsidence map by applying the geological and hydrogeological information of the aquifer system using an artificial neural network (ANN) combined with interferometric synthetic aperture radar (InSAR) and geospatial information system. The main problem with neural networks is providing the ground-truth dataset for training step. Therefore, the subsidence rate used as the network output was estimated using the InSAR time series analysis method. This study indicates the ANN approach is capable of knowing the mechanism of the land subsidence and can be used as a complementary of InSAR method to estimate the land subsidence with effective parameters and accessible data such as groundwater-level data especially in those areas in which measuring the subsidence was not feasible using InSAR. However, the results indicated that average groundwater depth and groundwater level decline were the most effective factors influencing subsidence in the study area using sensitivity analysis. (C) 2019 Society of Photo-Optical Instrumentation Engineers (SPIE) [DOI: 10.1117/1.JRS.13.044530]
\end{abstract}

Keywords: land subsidence; groundwater; artificial neural network; interferometric synthetic aperture radar; geospatial information system.

Paper 190461 received Jun. 18, 2019; accepted for publication Dec. 10, 2019; published online Dec. 31, 2019.

\section{Introduction}

Land subsidence is a geological phenomenon affecting a large number of cities worldwide, frequently caused by excessive extraction of groundwater, oil, and gas in addition to mining (mostly coal) or natural causes, ${ }^{1-5}$ with damaging effects to infrastructures and buildings such as towers, bridges, railways, and agricultural areas. ${ }^{6-10}$ Land subsidence caused by overexploitation of groundwater resources is one of the most common types around the world. For instance, San Joaquin Valley in California is one of the most famous plains in the world where land surface has subsided roughly $9 \mathrm{~m}$ from 1925 to 1977 due to withdrawal of groundwater. ${ }^{11}$ A balance occurs naturally in an undeveloped aquifer system where recharge mechanisms and discharge mechanisms of groundwater are equal. Pumping for urban or agricultural activities changes the balance of the system. According to Terzaghi's principle, groundwater extraction decreases pore water pressure and increases effective stress in soil layers, which in turn leads to soil consolidation. Land subsidence caused by the compaction of aquifer systems is frequently overlooked as a potential hazard and an environmental consequence of groundwater withdrawal.

*Address all correspondence to Mohsen Bagheri, E-mail: bagheri.m4@gmail.com

$1931-3195 / 2019 / \$ 28.00$ (c) 2019 SPIE 
Land subsidence induced by overexploitation of groundwater is essentially a slow process, with extremely nonlinear behavior and its amount is greatly dependent on the thickness and depth of the aquifer, decreases of pore water pressure, mechanical properties, materials forming the aquifer, and its surrounded soil layers. ${ }^{12}$ However, the process of quantitative assessment to predict land subsidence areas using numerical methods such as finite element and finite difference modeling involves a degree of approximation, especially when the exact characteristics of the aquifer are not available. This is due to the complex interactions between the different constructor factors of aquifer. For example in the Harquahala Plain, Arizona, only about $0.6 \mathrm{ft}$ of subsidence occurred in response to about $300 \mathrm{ft}$ of water-level decline. In contrast, in the vicinity of Willcox more than $5 \mathrm{ft}$ of subsidence occurred in response to just $200 \mathrm{ft}$ of water-level decline. ${ }^{13-15}$ Therefore, the mechanism of land subsidence in each region is specific to that region. Knowing about the subsidence behavior enables us to provide an efficient method for modeling and predicting land subsidence using effective parameters and accessible data such as groundwater-level data especially for those areas where there are restrictions on measuring land subsidence. There are different approaches for modeling the subsidence behavior. Some methods are based on analytical approaches, which try to model the groundwater flow followed by calibration of hydrogeological parameters of the aquifer systems. ${ }^{16}$ For implementation, however, a comprehensive knowledge of the aquifer system is required. Some other methods are based on just some measurements of the subsidence, specifically through time. These methods mainly try to fit a temporal model to subsidence time series so as to be able to predict the subsidence in near future. If the subsidence measurements are in space, the modeling is reduced to spatial interpolation of the subsidence. Another group of modeling approaches is based on artificial intelligence, ${ }^{17}$ e.g., artificial neural network (ANN). ANN is an efficient computing system whose central theme is borrowed from the analogy of biological neural networks. In an ANN, there are some computational units called neurons with weight and bias parameters, which should be carefully estimated in the training step according to some samples of the subsidence. After training the network, the subsidence can be completely simulated. However, the main challenge in using ANN is the training stage, which requires precise and dense training data, because proper training will lead to an accurate land subsidence prediction model. Kim et al. ${ }^{17}$ used the ANN method to model land subsidence around coal mines. To provide the training data, they established a number of pillars around the study area and measured the subsidence periodically using GPS. Furthermore, VaeziNejad et al. ${ }^{18}$ applied the ANN method for modeling land subsidence in Kerman city, using leveling measurements to monitor land subsidence.

Traditional methods, such as GPS and leveling observations, can measure the deformation in sparse points. These points are not sufficient for training a network whose purpose is to model the complex behavior of the subsidence. Using an insufficient number of training data may lead to overfitting of the network, which lacks adequate ability for generalization.

Among all space- and ground-based geodetic techniques, interferometric synthetic aperture radar (InSAR) method is able to produce measurements at high spatial resolution over a large area. Differential InSAR, using the phase difference known as interferogram, of two correlated synthetic aperture radar (SAR) images, has the ability to detect surface displacements to within a centimeter-to-millimeter accuracy. ${ }^{19}$ InSAR, however, fails to measure the surface deformation when the study area contains a significant amount of vegetation due to decorrelation effect. ${ }^{20}$ In this case, one method based on InSAR called persistent scatterer interferometry (PSI), which tries to monitor the deformation on coherent pixels, is applied. Dehghani et al. ${ }^{20}$ used PSI to measure the subsidence in the Tehran Plain. Because PSI is only able to measure the deformation at persistent scatterer (PS) pixels, they used ANN to estimate the subsidence at all pixels of the study area. They used the deformation measurements at PS pixels as training data and predicted the subsidence rate at non-PS pixels. Another method to address the decorrelation problem is InSAR small baseline subset (SBAS) time series analysis approach in which the processed interferograms are characterized by small baselines. However, some decorrelated pixels may be left in the final results with no correct estimate of the subsidence. Accordingly, the application of ANN can be helpful to model and estimate the subsidence at those pixels. Moreover, due to the large number of pixels in which the subsidence is correctly estimated, there is no insufficiency for training data.

According to the reasons mentioned above, the purpose of this study is to develop a method to model the mechanism of land subsidence in Rafsanjan Plain, Iran. First, the subsidence rate is 
estimated using InSAR SBAS time series analysis. Because the study area is covered by cultivated lands with a significant decorrelation effect, subsidence rate cannot be correctly estimated at the decorrelated pixels. An ANN using the effective geology and hydrogeology factors as input variables of the network will enable us to estimate the subsidence rate at those pixels. The required training data are provided by the high-quality InSAR measurements. Finally, sensitivity analysis is performed using the generated model to determine the most effective factor in subsidence occurrence.

\subsection{Study Area}

The Rafsanjan Plain is located in Kerman province in the southeast of Iran (Fig. 1). Subsidence in this region is one of the oldest phenomena and has continued up to this day. This plain is

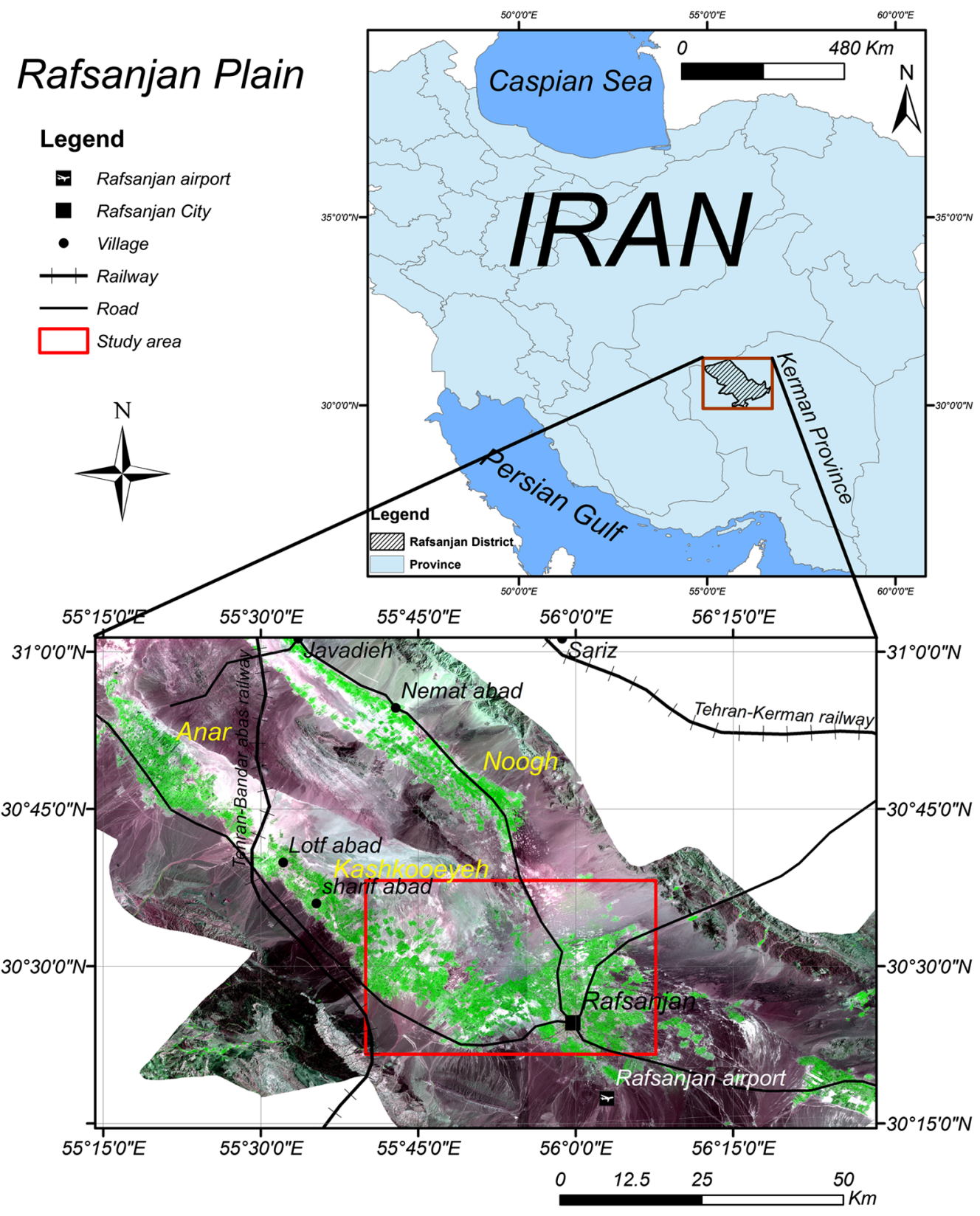

Fig. 1 Rafsanjan Plain. The red box represents the study area. The lower image is color composite of bands 7, 4, and 2 as red, green, and blue of ETM+ sensor of Landsat satellite. The cultivated lands are illustrated in green. 
rectangular in shape and divided into three main plains: the Rafsanjan-Kabootar Khan, AnarKashkooyeh, and Noogh plains. Most of the area is located in a graben, a lowered block bounded by faults, bordered by the Davaran Mountain on the north and Urmia-Dokhtar Mountain on the south and west. ${ }^{8}$ This plain has been filled with eroded materials from the surrounding mountains and lake sediments. Some scientists believe that the Rafsanjan Plain is the remains of an old lake from the Pleistocene geological age. ${ }^{21}$ Thus, the quaternary sediments in this area are composed of lake sediments formed from silt and clay, with fine crystals of salt and gypsum. Based on geophysical investigations, the average thickness of the aquifers in Rafsanjan-Kabootar Khan, Anar-Kashkooyeh, and Noogh plains has been determined to be 180, 100, and $20 \mathrm{~m}$, respectively. ${ }^{2}$ According to information obtained from 1968 to 1995, it was found that the amount of water consumption and the number of pumping wells in the Rafsanjan Plain have increased by a factor of 5 and 8 , respectively. ${ }^{8}$ Around 110,000 ha of this plain are covered by agricultural lands (mostly pistachio cultivation). The main cause of land subsidence is the excessive exploitation of groundwater for agricultural purposes (accounting for $\sim 91.2 \%$ of all extracted groundwater). ${ }^{2}$ The consequences of this subsidence include deep fractures on the ground surface, breakages in the internal casing of the wells, and changes in the slope of the water channels.

\section{Materials and Methods}

\subsection{Theory of Artificial Neural Network}

An ANN is an information-processing approach that is inspired by the way biological nervous systems, such as the brain, process information. It is composed of a large number of highly interconnected processing elements (neurons) working in unison to solve specific problems. ${ }^{22}$ Each neuron is a simple processing unit that responds to the weighted inputs it receives from other neurons. The arrangement of the nodes is referred to as the network architecture (Fig. 2). An ANN is usually a multilayered neural network that consists of an input layer, hidden layers, and an output layer. The hidden and output layer neurons process the input they receive via

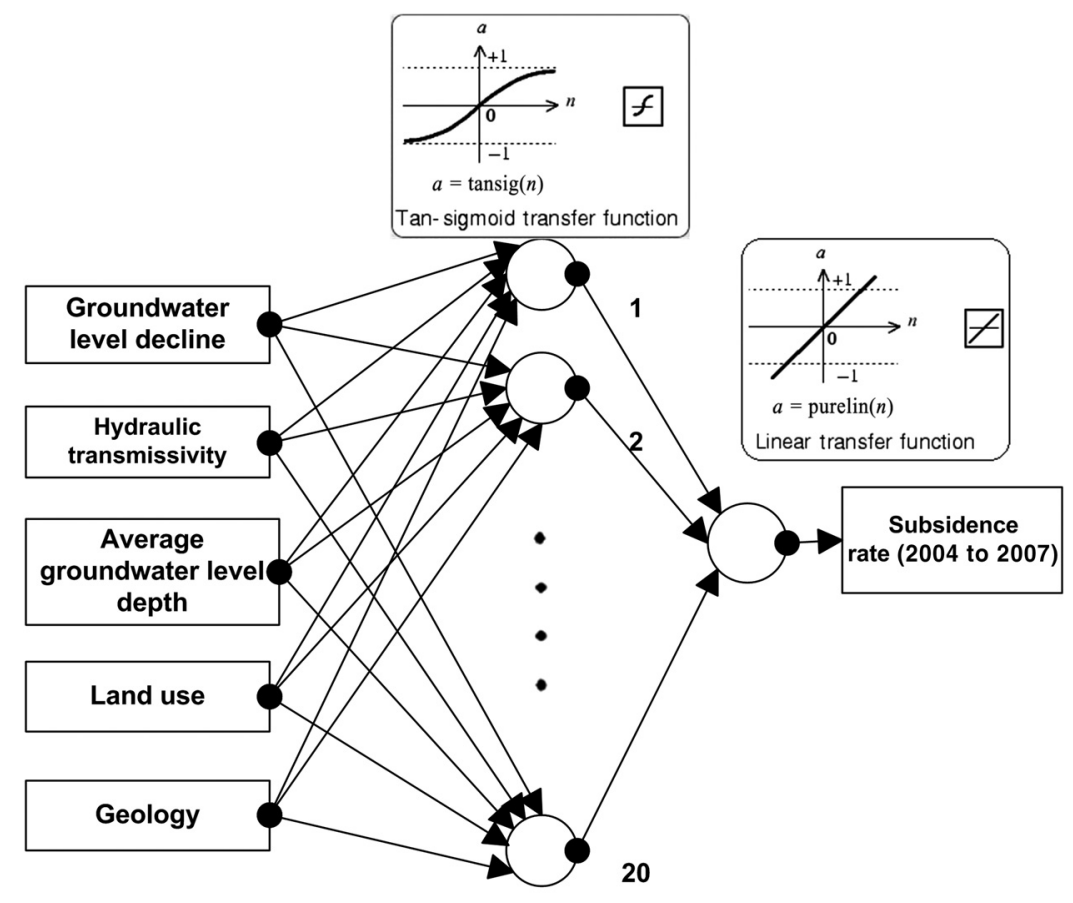

Input layer Hidden layer Output layer

Fig. 2 Architecture of ANN for assessment of land subsidence. 
multiplying each input by a corresponding weight, summing the product, and then processing the sum using a nonlinear transfer function to produce the result. The weight of an input is a number that, when multiplied by the input, gives the weighted input. These weighted inputs are then added together. An ANN is configured for a specific application, such as pattern recognition or data classification, through a learning process. In other words, the aim of an ANN is to build a model of the data-generating process so that the networks can produce and predict outputs from inputs that it has not previously seen. Learning in biological systems involves adjustments to the synaptic connections that exist between the neurons. The backpropagation algorithm is widely used for this purpose.

Backpropagation is the generalization of the Widrow-Hoff learning rule to multiple-layer networks and nonlinear differentiable transfer functions. The backpropagation algorithm is used to train the ANN by applying a set of associated input and output values. In principle, backpropagation provides a way to train networks with any number of hidden units arranged in any number of layers.

In the application of the backpropagation algorithm, two distinct passes of computation are distinguished. ${ }^{23}$ The first pass is referred to as the forward pass, with the second being referred to as the backward one. In the forward pass, the synaptic weights remain unaltered throughout the network, and the function signals of the network are computed on a neuron-by-neuron basis. The function signal, $y_{j}(n)$, appearing at the output of neuron $j$ is defined according to Eq. (1):

$$
y_{j}(n)=\phi\left[v_{j}(n)\right],
$$

where $v_{j}(n)$ is the induced local field of neuron $j$, which is defined by Eq. (2):

$$
v_{j}(n)=\sum_{i=0}^{m} \omega_{j i}(n) y_{i}(n)
$$

where $m$ is the total number of inputs applied to neuron $j, \omega_{j i}(n)$ is the synaptic weight connecting neuron $i$ to neuron $j$, and $y_{i}(n)$ is the input signal of neuron $j$ or, equivalently, the function signal appearing at the output of neuron $i$. The function $\varphi$ is usually a nonlinear function applied to the weighted sum of inputs before the signal propagates to the next layer. In this study, the tangent sigmoid [Eq. (3)] and linear [Eq. (4)] functions were applied to the hidden and output layers, respectively:

$$
\begin{gathered}
\phi(x)=\frac{1-e^{-2 x}}{1+e^{-2 x}}, \\
\phi(x)=x .
\end{gathered}
$$

In the next step, the output, $y_{j}(n)$, is compared to the desired response, $d_{j}(n)$, obtaining the error signal $e_{j}(n)$ for the $j$ 'th output neuron [Eq. (5)].

$$
e_{j}(n)=d_{j}(n)-y_{j}(n) .
$$

The instantaneous value of $\xi(n)$, which refers to the total error energy, is obtained by summing $(1 / 2) \times e_{j}^{2}(n)$ over all neurons in the output layer. The objective of the learning process is to adjust the free parameters of the network (i.e., synaptic weights and bias levels) to minimize $\xi_{a v}$. Let $N$ denote the total number of patterns (examples) contained in the training set. The average squared error energy is obtained by summing $\xi(n)$ over all $N$ and then normalizing with respect to the set size $N$, as shown in Eq. (6).

$$
\xi_{a v}=\frac{1}{N} \sum_{n=1}^{N} \xi(n)
$$

In the backpropagation learning algorithm, the weights are updated on a pattern-by-pattern basis until one epoch, that is, one complete presentation of the entire training set, has been dealt with. ${ }^{23}$ The adjustments to the weights are made in accordance to the respective errors computed 
for each pattern presented to the network. Thus, the forward phase of computation begins at the first hidden layer by presenting it with the input vector and terminates at the output layer by computing the error signal for each neuron of this layer.

The backward pass, on the other hand, starts at the output layer by passing the error signals backward through the network, layer by layer, and recursively computing the $\delta$ (the local gradient) for each neuron according to Eq. (7). It then applies a correction, $\Delta \omega_{j i}(n)$, to the synaptic weight, $\omega_{j i}(n)$, which is defined by the delta rule [Eq. (8)]:

$$
\begin{gathered}
\delta_{j}(n)=\phi_{j}^{\prime}\left[v_{j}(n)\right] \sum_{k} \delta_{k}(n) \omega_{k j}(n) \quad \text { Neuron } j \text { is hidden } \\
\Delta \omega_{j i}(n)=\alpha \Delta \omega_{j i}(n-1)+\eta \delta_{j}(n) y_{i}(n)
\end{gathered}
$$

where $\eta$ is the learning-rate parameter of the backpropagation and $\alpha$ is usually a positive number called the momentum constant.

The factor $\varphi_{j}^{\prime}\left[v_{j}(n)\right]$ involved in the computation of the local gradient $\delta_{j}(n)$ depends solely on the activation function associated with hidden neuron $j$, and $\delta_{k}(n)$ requires knowledge of the error signals $e_{k}(n)$ for all neurons that lie in the layer that is located on the right side of hidden neuron $j$ and directly connect to neuron $j$. Here $\omega_{k j}(n)$ consists of the synaptic weights associated with these connections.

\subsection{Data Source}

\subsubsection{Input factors to ANN}

In the intelligent approach used in this research, the input variables of the network are the geological and hydrogeological parameters of the aquifer system. Since subsidence occurs due to the overexploitation of groundwater, its spatial pattern matches the cultivated lands (this is verified by the InSAR measurements and field observations). ${ }^{2}$ Investigations conducted by an organization called Ma'ab Consulting Engineers' Company identified that the Rafsanjan Plain contains only one unconfined aquifer system in which all pumping wells have been drilled. ${ }^{2}$ As a whole, the following factors functioned as input variables for the ANN:

- Hydraulic transmissivity, which is the ability to pass water through the aquifer

- Average groundwater level depth

- Groundwater level decline

- Land use

- Geology

Three of these input factors, namely the hydraulic transmissivity, average groundwater level depth, and groundwater level decline, were produced using information on pumping and piezometric wells provided by the Kerman Regional Water Organization. The inverse distance weighting interpolation method was used to produce the final continuous maps. The last two input factors, land use and geology, were produced using the database of the State Geological Organization. A part of the Rafsanjan Plain, indicated by the red polygon shown in Fig. 3 was selected as the study area according to the proper density of pumping and piezometric wells. Thus, all input and output factors were cropped based on the selected area in a grid of 931 rows and 558 columns. The input factors to the ANN are shown in Figs. 4-8.

\subsubsection{Interferometric synthetic aperture radar data}

To investigate land subsidence in the Rafsanjan Plain, 17 Envisat ASAR images spanning between June 2004 and August 2007 and acquired in ascending mode (track 56) were used (Table 1).

InSAR is a radar technique used in geodesy and remote sensing. This method uses two or more SAR images to measure the surface deformation projected along the radar line-of-sight (LOS) direction using differences in the phase of the pulses returning to the satellite. ${ }^{19,24,25}$ 
Bagheri et al.: Assessment of land subsidence using interferometric synthetic aperture radar...

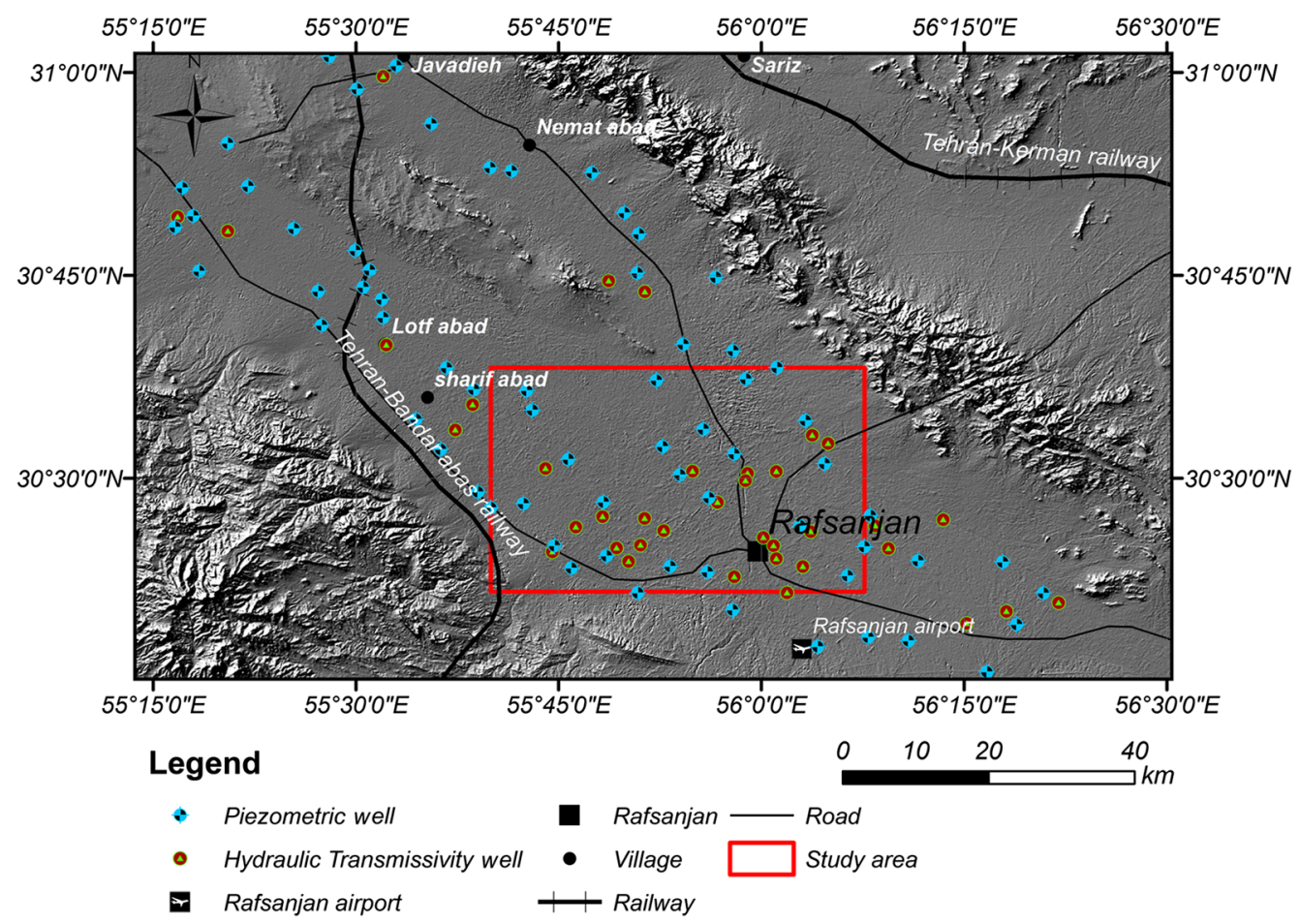

Fig. 3 Spatial distribution of piezometric wells and wells in which the hydraulic transmissivity has been measured. The red box represents the study site used in this research.

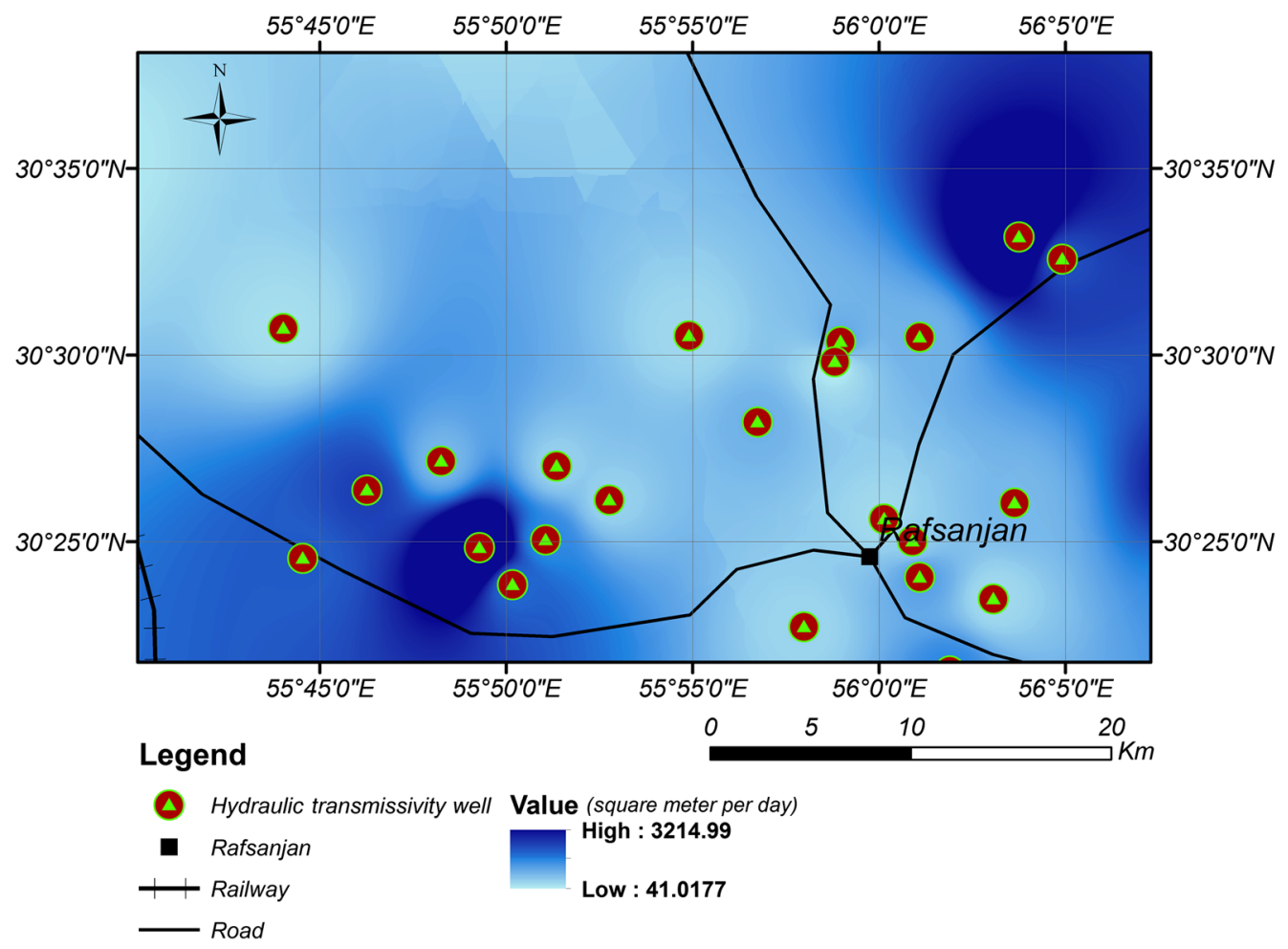

Fig. 4 Hydraulic transmissivity map.

Detecting changes in the position of the Earth's surface requires two radar images of a selected area taken from approximately the same position in space but at two different times. SAR interferometry makes use of the phase shift information by subtracting the phase value from one SAR data acquisition from that of another, for the same point on the ground. The resulting phase 


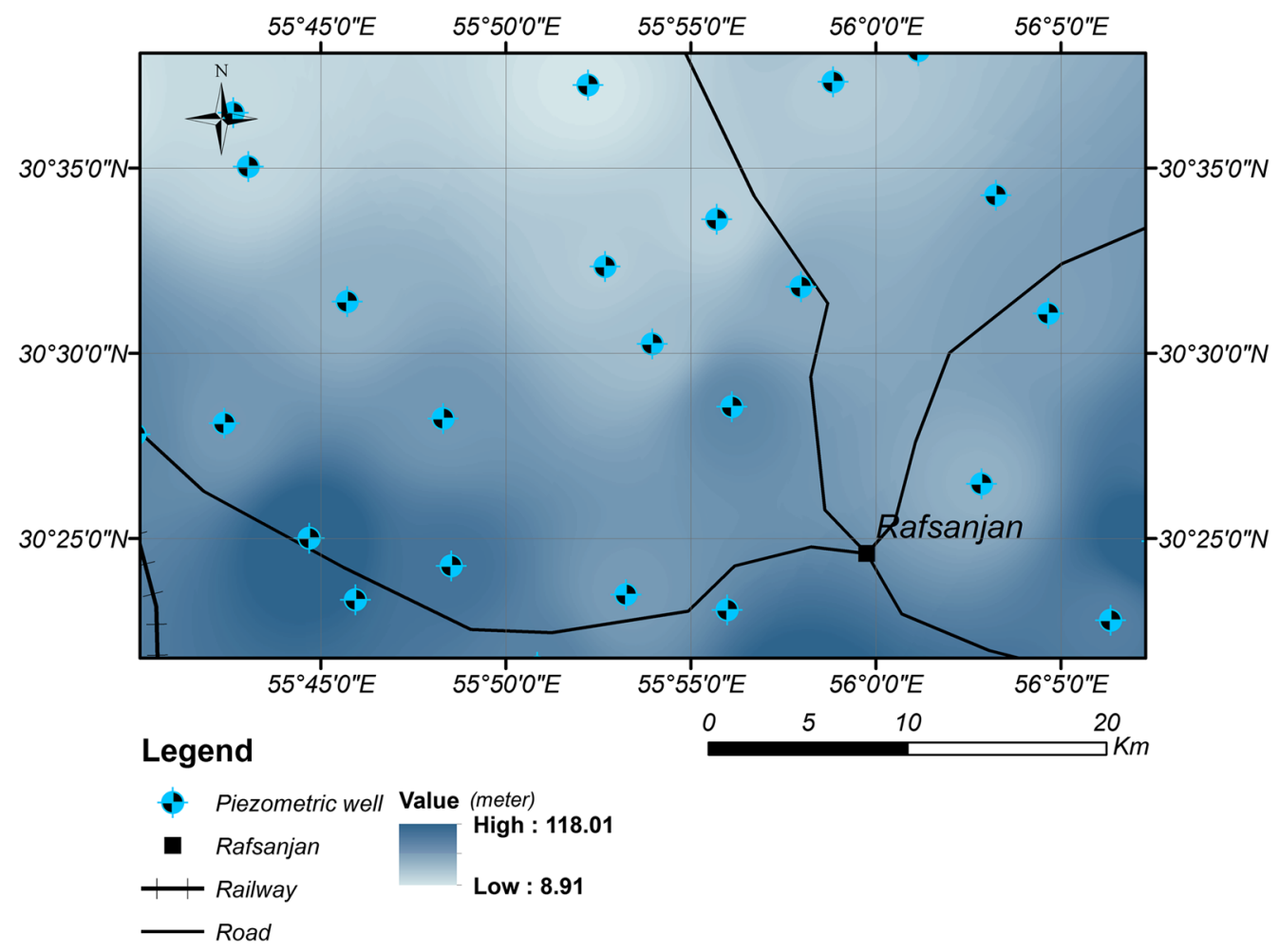

Fig. 5 Average groundwater level depth map.

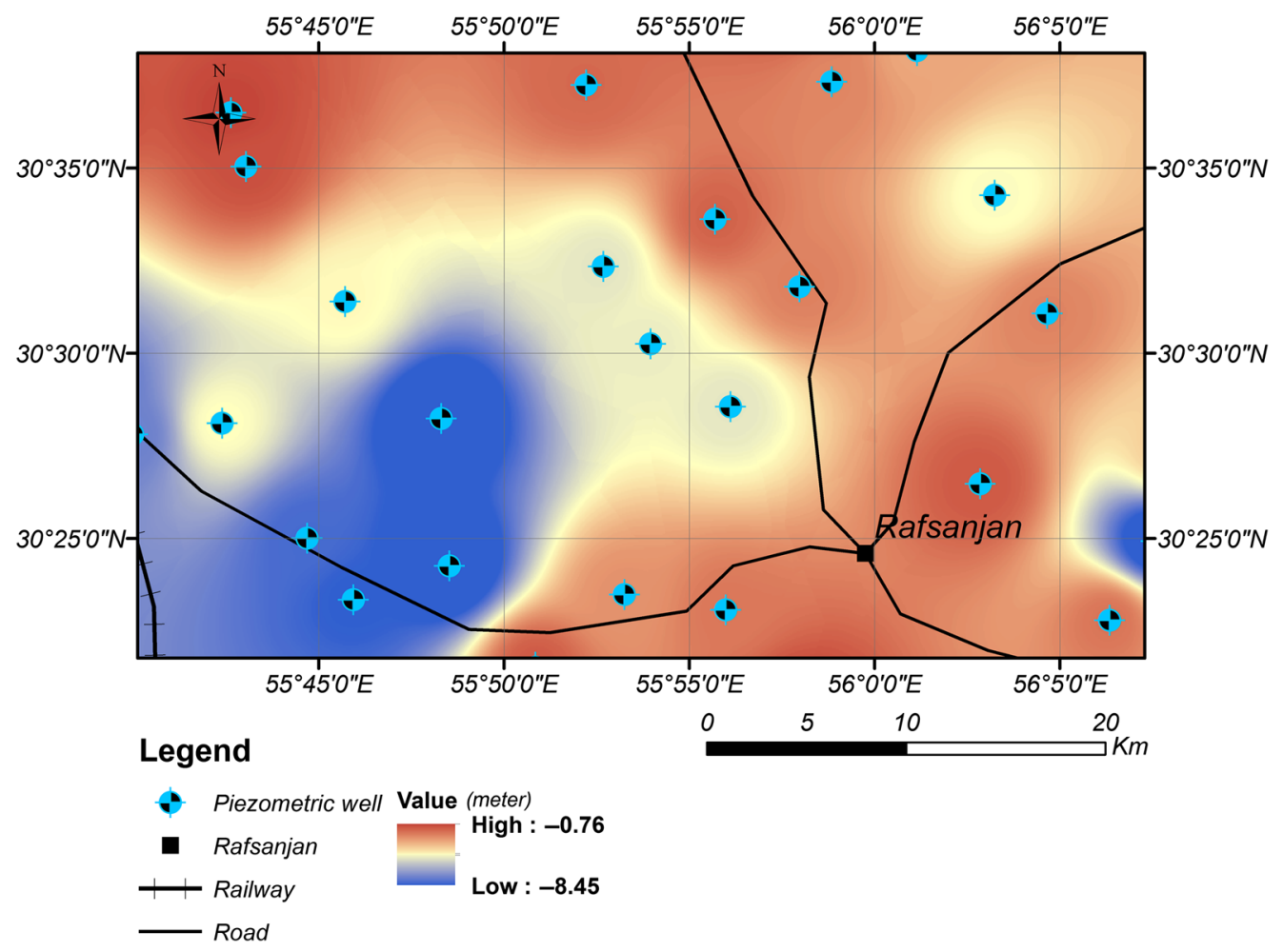

Fig. 6 Groundwater level decline map.

difference, represented by interferometric fringes, is directly related to topographic height. However, as time passes, the height of the Earth's surface can change, so in fact an interferogram contains information not only on topography but also on changes in topography that may have occurred in the period spanned by the data acquisition. Differential interferometry is used to 
Bagheri et al.: Assessment of land subsidence using interferometric synthetic aperture radar...

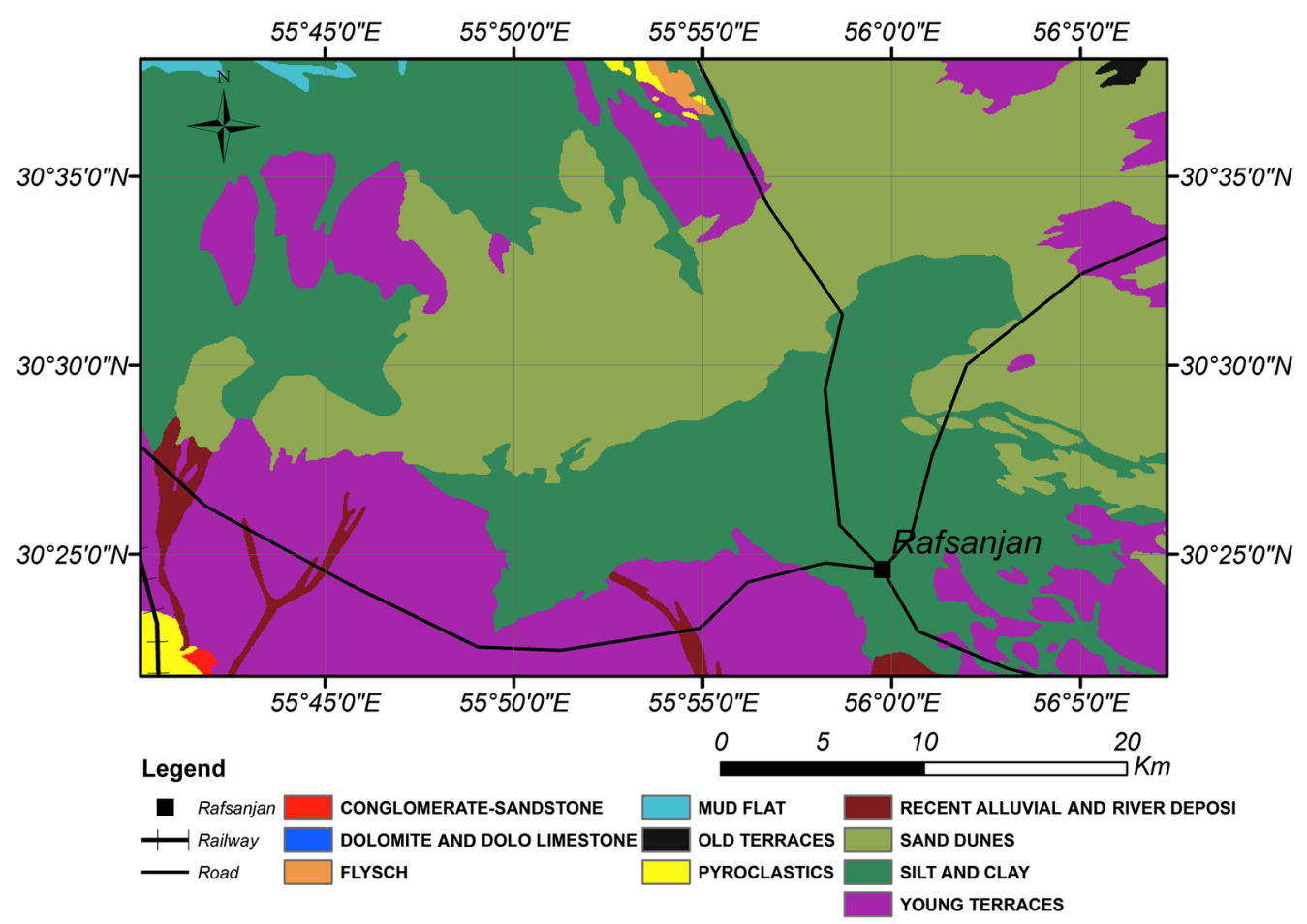

Fig. 7 Geology map.

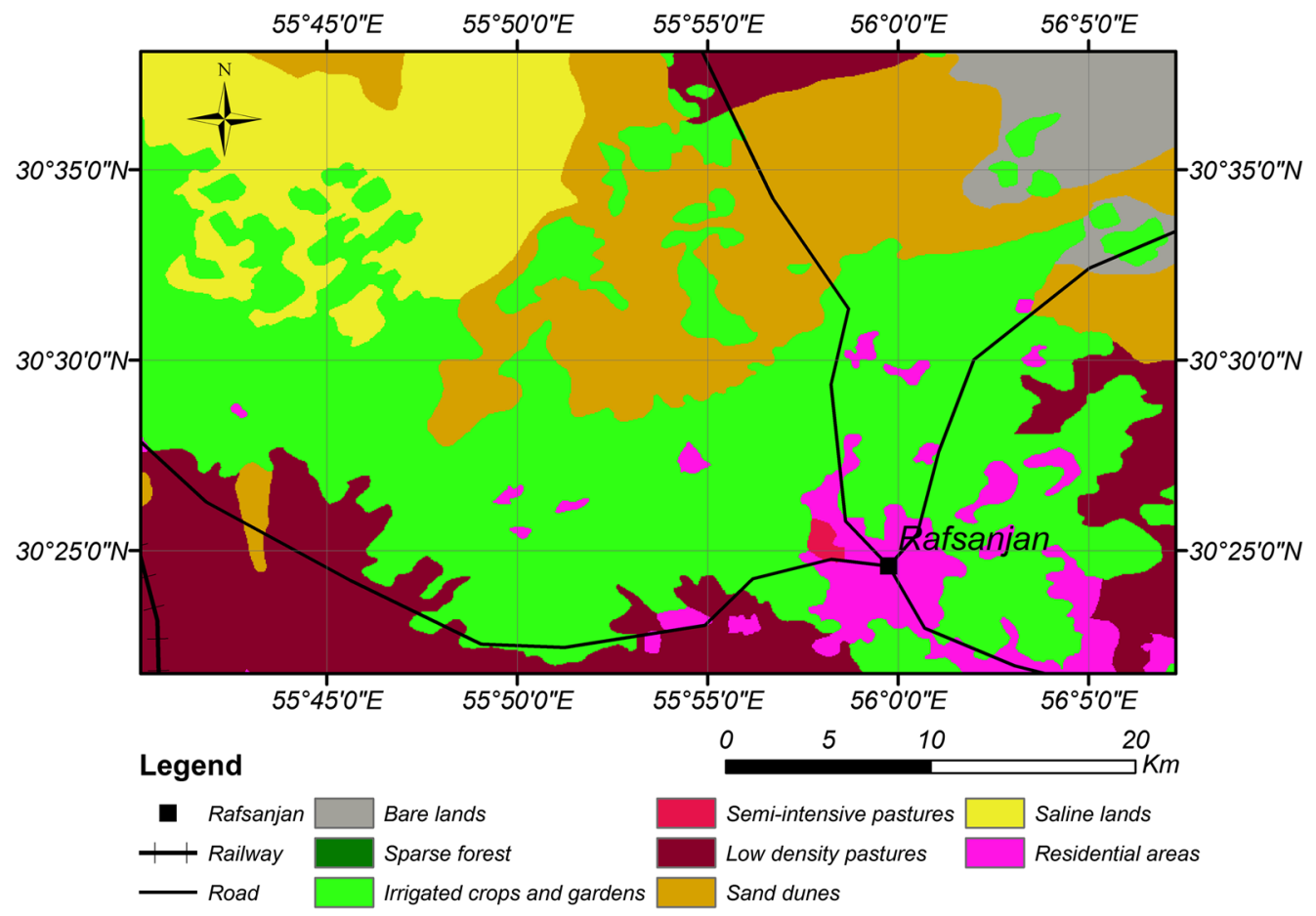

Fig. 8 Land use map.

detect these changes in topography. In its simplest form, an interferogram, including different phase components, as shown in Eq. (9), is first created.

$$
\Delta \varphi_{\text {Int }}=\Delta \varphi_{\text {Def }}+\Delta \varphi_{\text {Topo }}+\Delta \varphi_{\text {Earth-curv }}+\Delta \varphi_{\text {Atm }}+\Delta \varphi_{\text {Noise }},
$$

where $\Delta \varphi_{\text {Int }}$ is the generated interferogram, $\Delta \varphi_{\text {Def }}$ is the deformation phase component, $\Delta \varphi_{\text {Topo }}$ is the phase contribution to the topography, $\Delta \varphi_{\text {Earth-curv }}$ is the phase component due to the Earth 
Bagheri et al.: Assessment of land subsidence using interferometric synthetic aperture radar...

Table 1 Acquisition dates of Envisat ASAR images used in the study area.

\begin{tabular}{|c|c|c|c|}
\hline Day no & Acquisition date & Orbit & Sensor \\
\hline$d_{0}$ & 25 June 2004 & 12,134 & Envisat ASAR \\
\hline$d_{1}$ & 3 September 2004 & 13,136 & Envisat ASAR \\
\hline$d_{2}$ & 12 November 2004 & 14,138 & Envisat ASAR \\
\hline$d_{3}$ & 17 December 2004 & 14,639 & Envisat ASAR \\
\hline$d_{4}$ & 21 January 2005 & 15,140 & Envisat ASAR \\
\hline$d_{5}$ & 25 February 2005 & 15,641 & Envisat ASAR \\
\hline$d_{6}$ & 1 April 2005 & 16,142 & Envisat ASAR \\
\hline$d_{7}$ & 10 June 2005 & 17,144 & Envisat ASAR \\
\hline$d_{8}$ & 15 July 2005 & 17,645 & Envisat ASAR \\
\hline$d_{9}$ & 28 October 2005 & 19,148 & Envisat ASAR \\
\hline$d_{10}$ & 21 April 2006 & 21,653 & Envisat ASAR \\
\hline$d_{11}$ & 13 October 2006 & 24,158 & Envisat ASAR \\
\hline$d_{12}$ & 26 January 2007 & 25,661 & Envisat ASAR \\
\hline$d_{13}$ & 2 March 2007 & 26,162 & Envisat ASAR \\
\hline$d_{14}$ & 6 April 2007 & 26,663 & Envisat ASAR \\
\hline$d_{15}$ & 20 July 2007 & 28,166 & Envisat ASAR \\
\hline$d_{16}$ & 24 August 2007 & 28,667 & Envisat ASAR \\
\hline
\end{tabular}

curvature, $\Delta \varphi_{\text {Atm }}$ is the phase component due to different atmospheric phase delays at both acquisitions, and $\Delta \varphi_{\text {Noise }}$ is mainly due to the temporal and spatial decorrelation effects. Different phase components should be estimated and removed from the interferogram to obtain the phase contribution to the surface deformation. Here $\Delta \varphi_{\text {Earth-curv }}$ is estimated using the amount of spatial perpendicular baseline. A residual phase called the orbital errors remains due to imprecise value of the baseline, which is further removed by interferogram flattening. ${ }^{26}$ The $\Delta \varphi_{\text {Topo }}$ is estimated using an existing digital elevation model (DEM) and subtracted from $\Delta \varphi_{\text {Int }}$ to generate the differential interferogram. The $\Delta \varphi_{\text {Noise }}$ is reduced by filtering. After phase unwrapping, the LOS displacement map is extracted. To decompose the LOS displacement into different directions, i.e., north-south, east-west, and up-down, more than two different acquisition geometries are required, though the sensitivity of InSAR measurements to the ground displacement along the north-south direction is negligible. The $\Delta \varphi_{\text {Atm }}$ can be finally mitigated by incorporating a smoothing constraint in the time series analysis of a significant number of interferograms.

To produce the subsidence map of the study area, the InSAR was used using the SBAS technique. This was done as the study area is covered by cultivated lands whose scattering behavior changes quite rapidly. ${ }^{27}$ The maximum spatial and temporal baselines were $300 \mathrm{~m}$ and 210 days, respectively. In total, according to the specified thresholds for temporal and spatial baselines, 23 interferograms was selected (Fig. 9). Finally, time series analysis was used to calculate the subsidence rate from June 2004 to August 2007 (Fig. 10). All InSAR processing was carried out using Doris software, and in order to remove topography fringes from all interferograms, the 1-arc sec ASTER DEM was used. It should be noted, as shown in Fig. 9, that the temporal and spatial baselines in three interferograms, 1 April 2005 to 10 June 2005, 3 September 2004 to 21 January 2005, and 21 April 2006 to 13 October 2006, which have been shown using dash line, are more than defined threshold. However, in order to establish continuity 


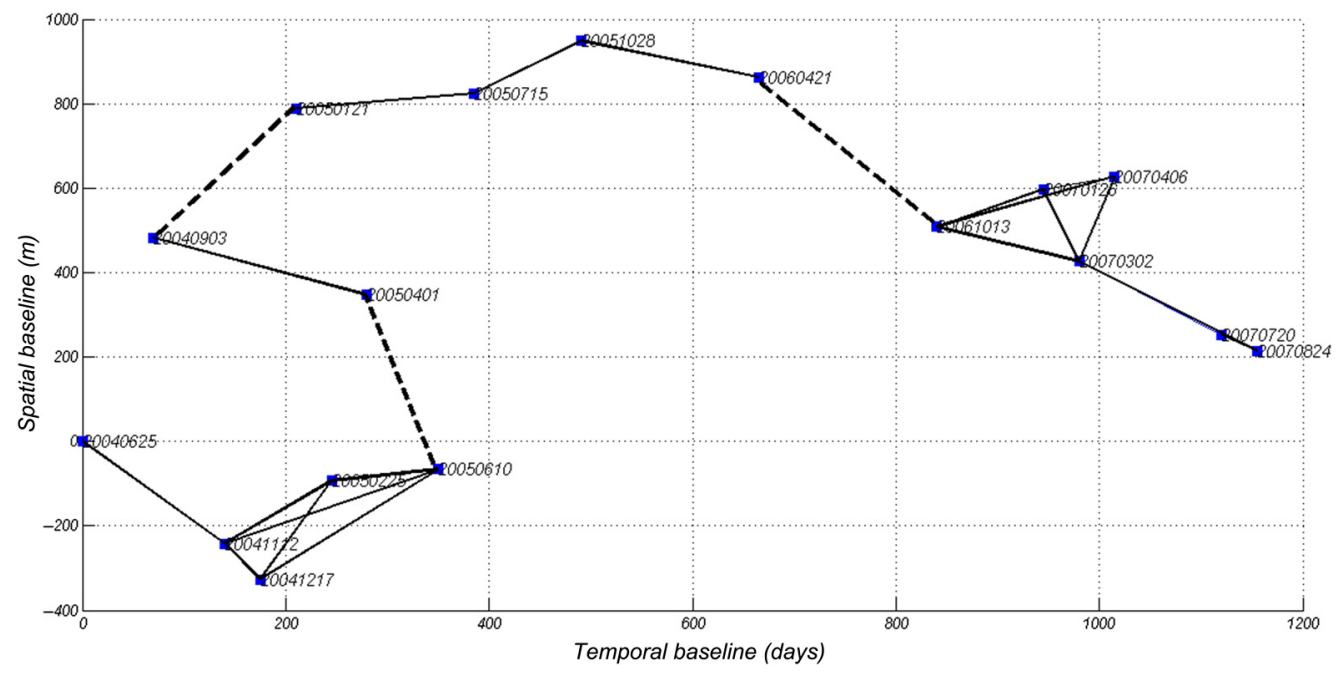

Fig. 9 Interferograms used in this study.

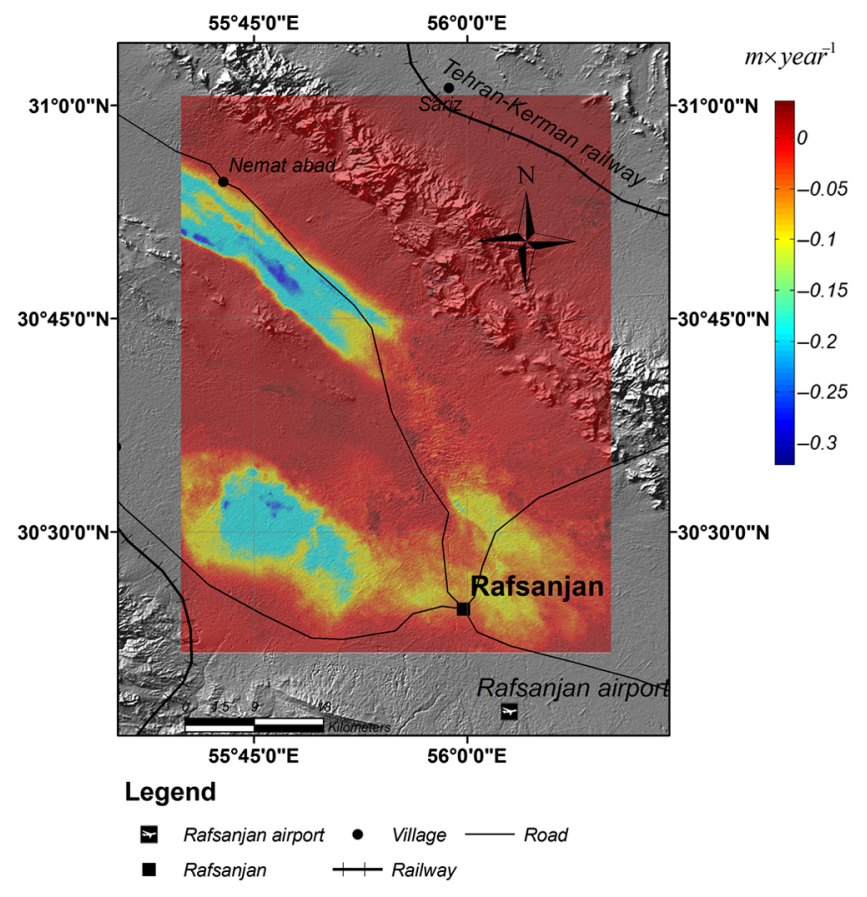

Fig. 10 Mean displacement velocity map of Rafsanjan Plain (June 2004 to August 2007). The map is overlaid on the topography map of 1 arc-second ASTER data.

between interferogram chains we have to use them. The estimated subsidence rates were applied to the training stage of the ANN as the output layer.

\subsection{Assessment of Land Subsidence Based on Artificial Neural Network}

In this study, a neural network was used to model subsidence in the Rafsanjan Plain. The input factors were prepared in the GIS, and the output layer was produced using InSAR. The flowchart of the model used is illustrated in Fig. 11. What follows is an explanation of the different steps of this process.

To determine the optimal weights in the training phase, the Levenberg-Marquardt (LM) algorithm was used. The LM curve-fitting method is actually a combination of two minimization approaches: the gradient descent method and the Gauss-Newton method. ${ }^{28,29}$ In the gradient 


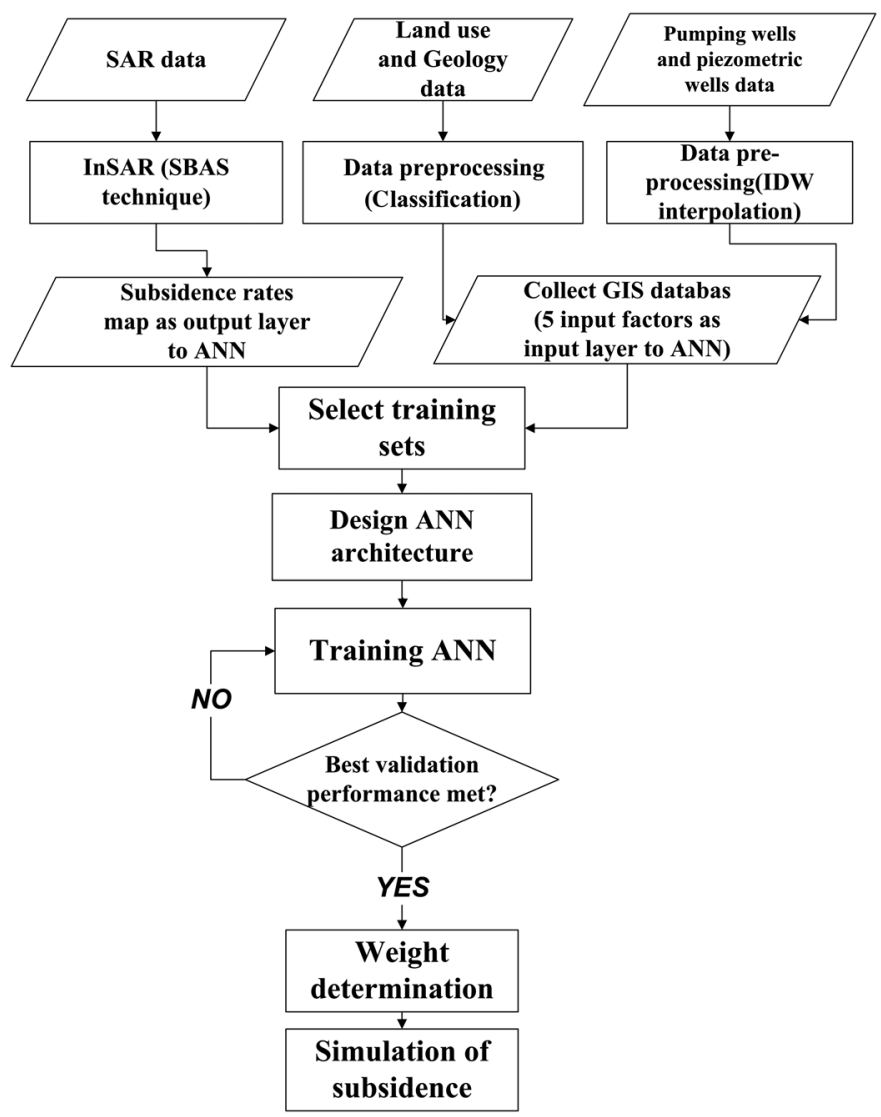

Fig. 11 Flowchart of the proposed method for land subsidence modeling.

descent method, the sum of the squared errors is reduced by updating the parameters in the direction of the greatest reduction of the least squares objective. In the Gauss-Newton method, the sum of the squared errors is reduced by assuming that the least squares function is approximately quadratic in the parameters near the optimal solution. ${ }^{29}$ In essence, the LM method acts more like a gradient descent method when the parameters are far from their optimal values and more like the Gauss-Newton method when the parameters are close to their optimal values. The LM method uses the following equation to update the network weights [Eq. (10)]:

$$
\omega_{k+1}=\omega_{k}-\left\{J^{T} J+\mu\left[\operatorname{diag}\left(J^{T} J\right)\right]\right\}^{-1} J^{T} d,
$$

where $J$ is the Jacobian matrix, which contains the first derivatives of the network errors with respect to the weights and biases, and $d$ is a vector of network errors. Small values of the parameter $\mu$ result in a Gauss-Newton update, whereas large values of $\mu$ result in a gradient descent update. ${ }^{28,29}$ The parameter $\mu$ is initialized to be large. If an iteration happens to result in a worse approximation, $\mu$ is increased. As the solution approaches the minimum, the value of $\mu$ is decreased, the LM method approaches the Gauss-Newton method and the solution typically converges rapidly to the local minimum.

As already mentioned, five geological and hydrogeological information factors were used as the input variables in the ANN while the InSAR-derived deformation rate was applied as the output of the network. In this study, a network was designed with one hidden layer containing 20 neurons. An LM training method with a $\mu$ value of 0.001 was used in order to estimate the weights and biases. For the purpose of training, test, and validation of the network, 40,000 samples out of the total number of $\sim 500,000$ pixels were randomly selected. Updating the network weights was continued until there was a downward trend in the mean square error (MSE) for evaluating data in each epoch. After a series of successive epochs, the MSE reached a constant value and finally began to ascend. At this point, the network training was stopped. In the final step, the model MSE was evaluated by a test dataset. The MSE was estimated as 0.3 in epoch 
285. After the training and evaluation stages, the calculated weights were frozen for use in the simulation stage. The subsidence rate was then simulated for all the pixels of the study area.

\section{Results and Discussion}

Neural network training was repeated several times, with the results presented in this paper belonging to the best-trained network. The subsidence rates simulated using the neural network and the InSAR-derived subsidence rates are illustrated in Figs. 12 and 13.

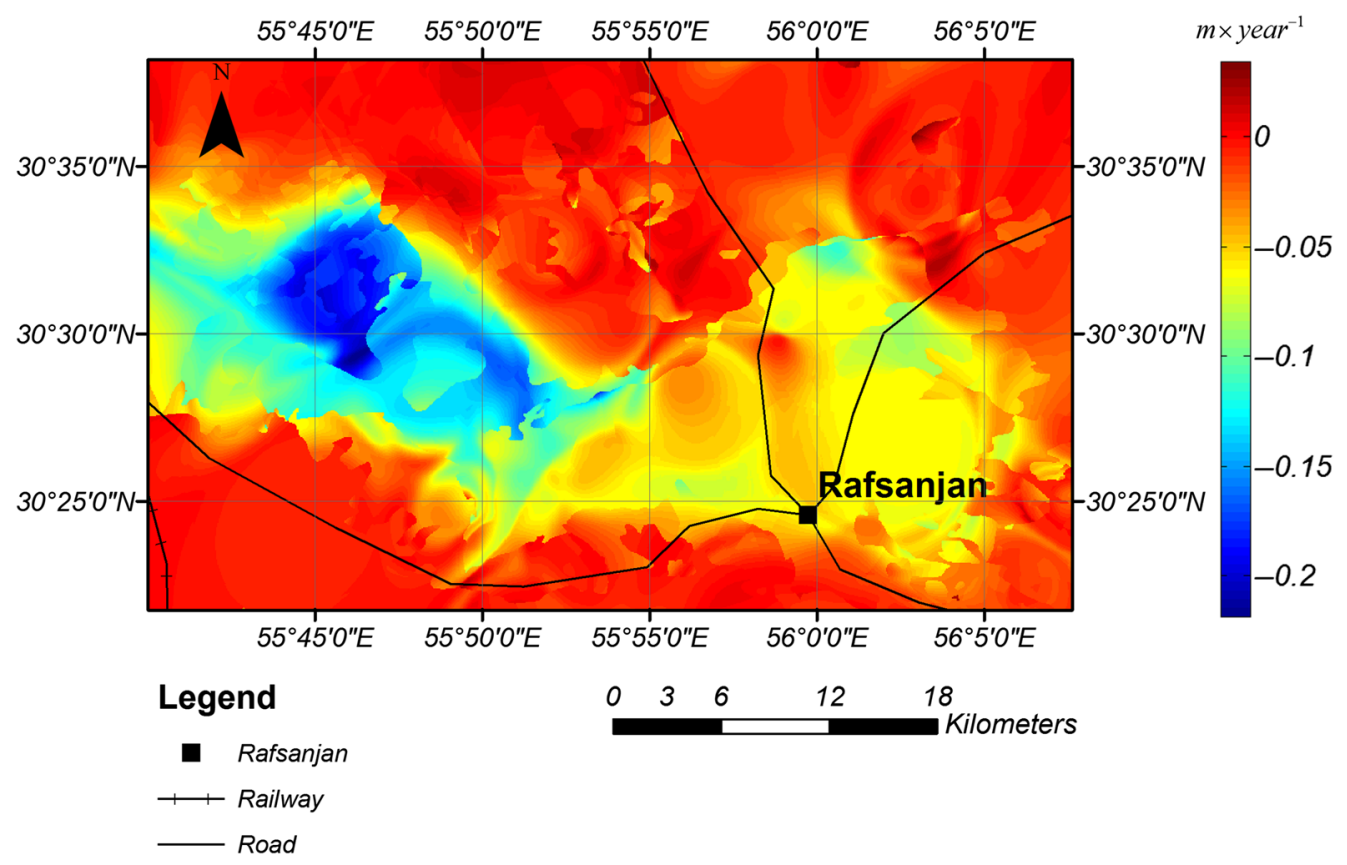

Fig. 12 Mean displacement velocity map that is modeled by ANN.

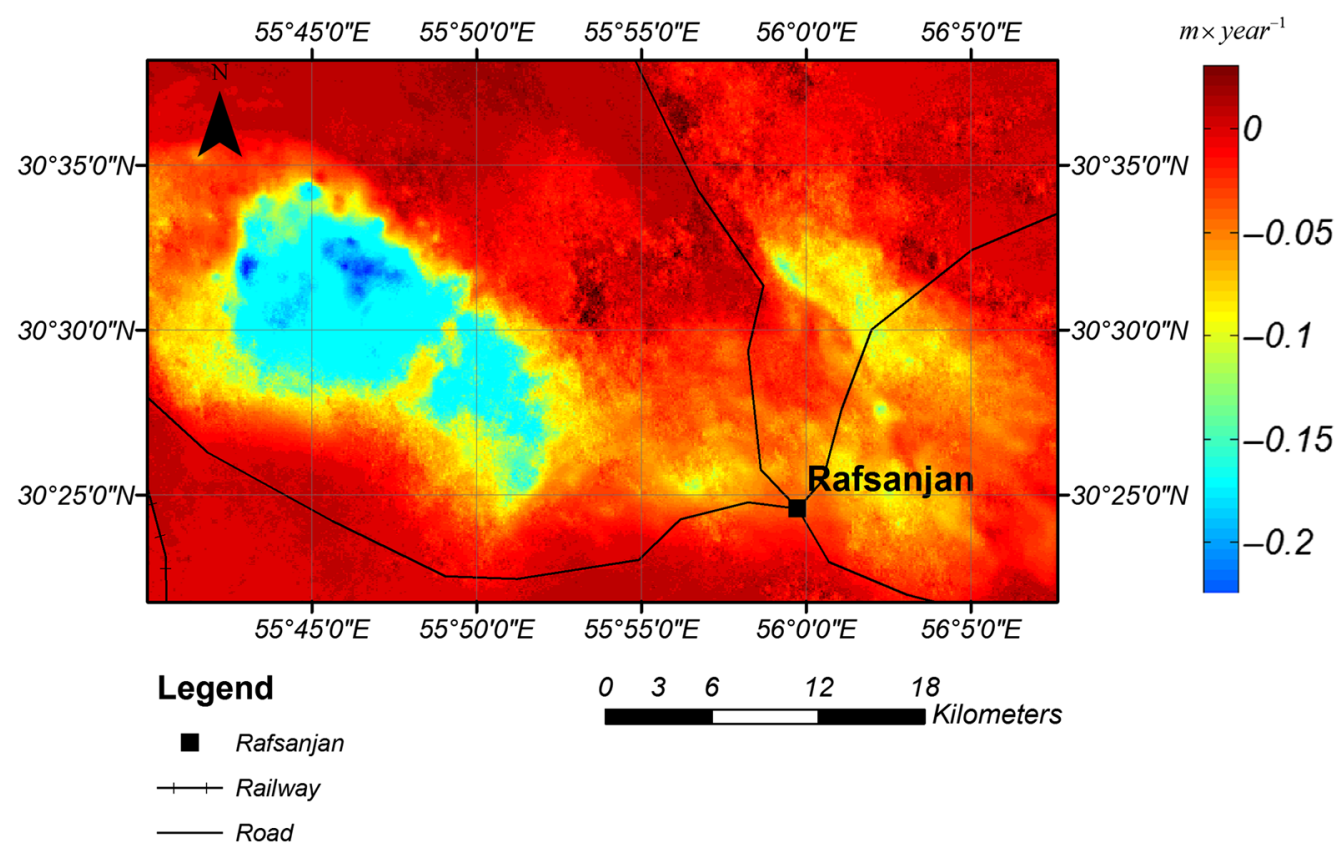

Fig. 13 InSAR-derived deformation rate. 


\subsection{Validation}

Validation was performed by comparing the subsidence rates map obtained from the InSAR method with the results of the neural network. The residual map was produced via subtracting the ANN results from the InSAR-derived subsidence rates (Fig. 14). The residual map shows the model error. As shown in Fig. 14, assessment of the overwhelming majority of the subsidence was possible using the ANN. This fact indicates that the network had been properly trained. Figure 15 shows the histogram of the model error. The histogram looks like the Gaussian distribution function that represents the concentration of error around zero. The estimated root mean square error (RMSE) of $0.0183 \mathrm{~m} \times$ year $^{-1}$ is an indication of the high accuracy of the model.

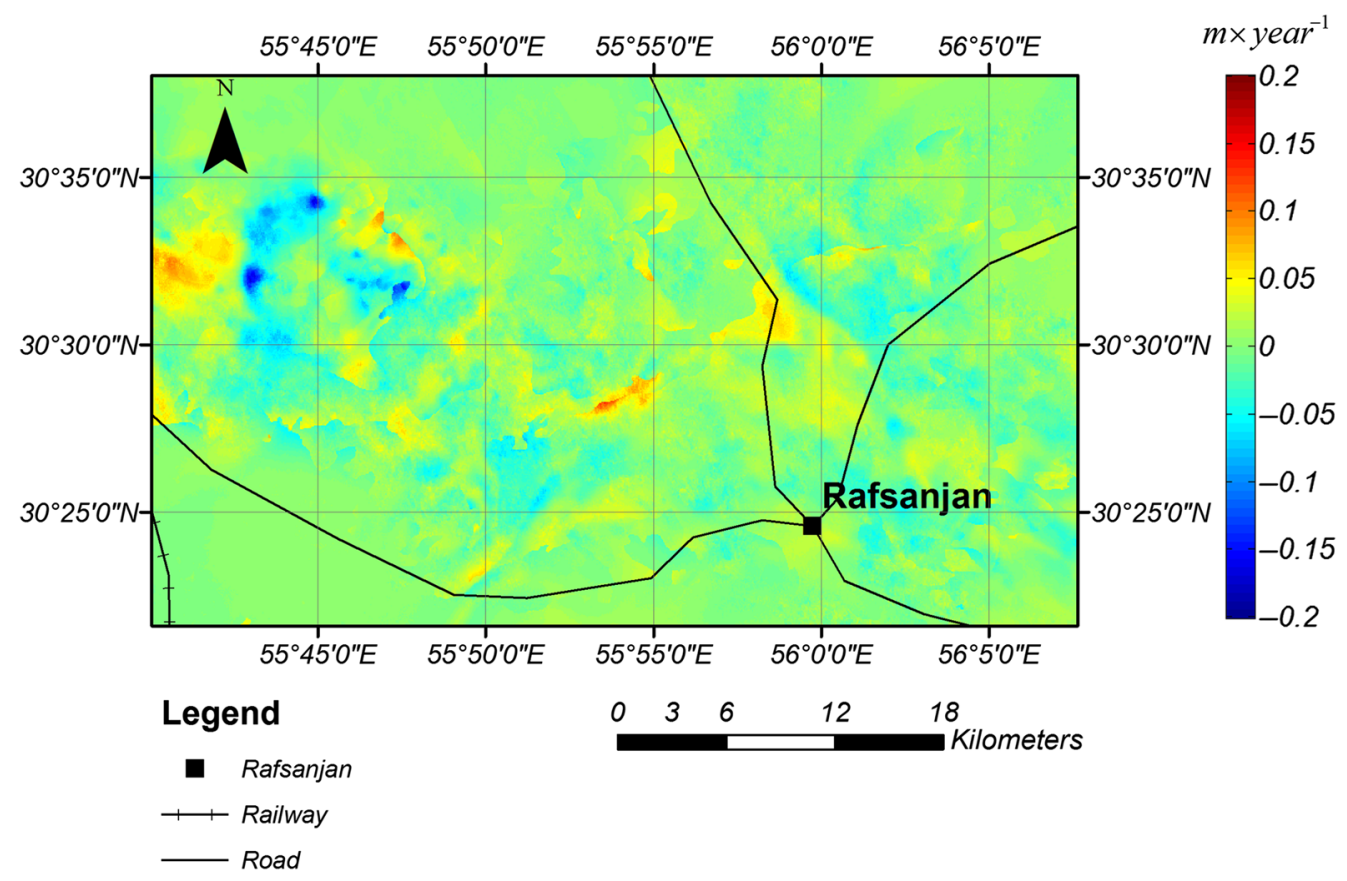

Fig. 14 The residual map obtained from the subtraction of ANN results from the InSAR-derived rates.

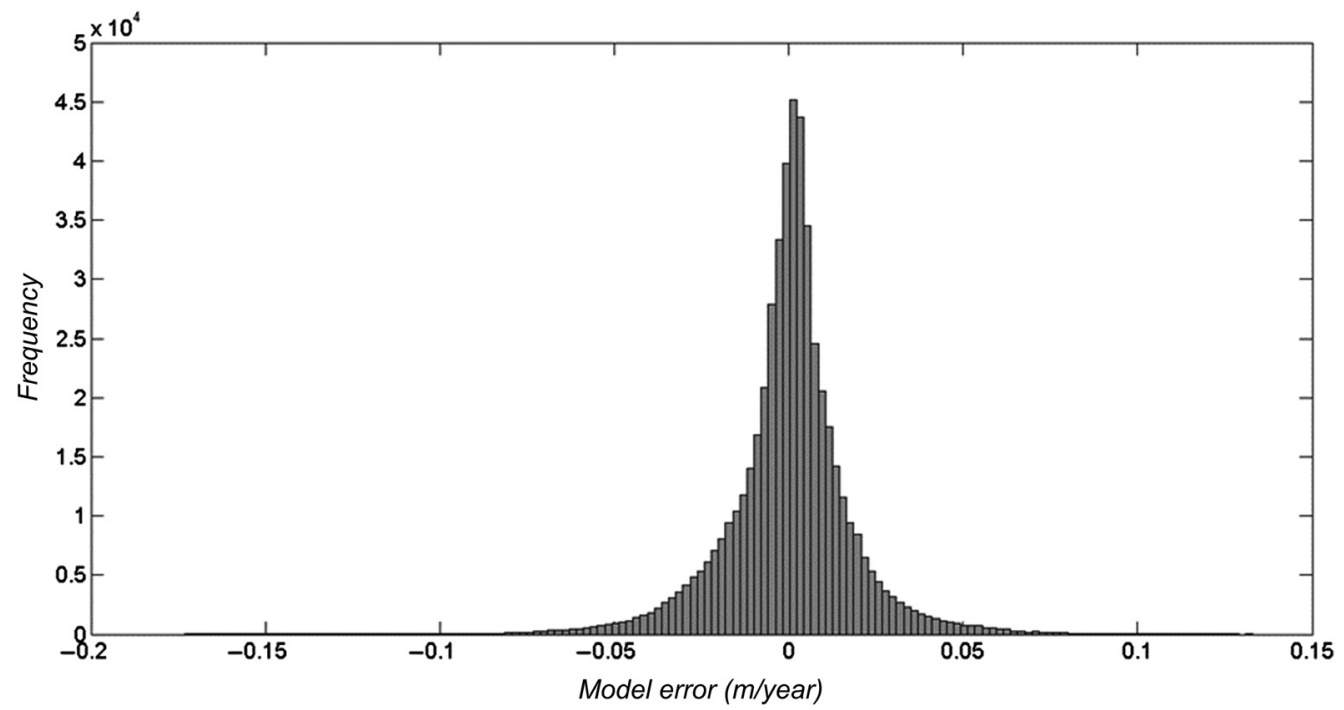

Fig. 15 Histogram of the model error. The error distribution is similar to the Gaussian distribution function with the mean value of zero. 
Moreover, the correlation between the outputs of the network and the desired targets was computed to further evaluate the model. The correlation was then examined for the training, test, and evaluation datasets separately. In statistics, the Pearson product-moment correlation coefficient (PCC) is a measure of the linear correlation (dependence) between two variables $X$ and $Y$, giving a value between +1 and -1 inclusive, where 1 is the total positive correlation, 0 is the no correlation, and -1 is the total negative correlation. It is widely used in the sciences as a measure of the degree of linear dependence between two variables. The PCC indicates the strength of a linear relationship between two variables, but its value generally does not completely characterize their relationship. ${ }^{30}$ It was developed by Karl Pearson from a related idea introduced by Francis Galton in the 1880 s. $^{31,32}$ PCC can be applied to both the population and the sample. When applied to a population, it is commonly represented by the Greek letter $\rho$ and may be referred to as the population Pearson correlation coefficient. The formula for $\rho$ is defined according to Eq. (11).

$$
\rho_{X, Y}=\frac{\operatorname{COV}(X, Y)}{\sigma_{X} \sigma_{Y}}
$$

where $\operatorname{COV}(X, Y)$ is the covariance and $\sigma_{X}$ is the standard deviation of $X$. In this case, PCC when applied to a sample is commonly represented by the letter $R$ and may be referred to as the sample correlation coefficient or the sample Pearson correlation coefficient. We can obtain a formula for $R$ by substituting estimates of the covariance and variances based on a sample into the equation above. So if we have one dataset $\left\{x_{1}, \ldots, x_{n}\right\}$ containing $n$ values and another dataset $\left\{y_{1}, \ldots, y_{n}\right\}$ containing $n$ values, then that formula for $R$ is defined according to Eq. (12):

$$
R_{x y}=\frac{\sum_{i=1}^{n}\left(x_{i}-\bar{x}\right)\left(y_{i}-\bar{y}\right)}{\sqrt{\sum_{i=1}^{n}\left(x_{i}-\bar{x}\right)^{2}} \sqrt{\sum_{i=1}^{n}\left(y_{i}-\bar{y}\right)^{2}}},
$$

where $n, x_{i}$, and $y_{i}$ are defined as above, and $\bar{x}=1 / n \sum_{i=1}^{n} x_{i}$ is the sample mean: the term for $\bar{y}$ is similar.

For this study, the desired targets $T$ were plotted versus the network outputs $Y$, and the regression line was calculated (Fig. 16). The concentration of points around the line $Y=T$ represents the high correlation between the calculated and the desired targets, and this means that the network could indicate a predictive linear relationship that can be exploited in practice. The correlation was estimated as 0.92 using Eq. (12) for the three datasets. Furthermore, the regression lines fitted to the points for all three datasets have little deviation from the line $Y=T$. Equations of the regression lines are presented in Table 2.

\subsection{Sensitivity Analysis}

Neural network-based sensitivity analysis was performed in order to identify the parameter with the greatest impact on the assessment of the land subsidence in the Rafsanjan Plain. One method for carrying out sensitivity analysis is presented by Hashem ${ }^{33}$ and Klimasauskas ${ }^{34}$ that examines the partial derivative of the network output with respect to its inputs.

In this study, to identify the parameter having the most significant impact on Rafsanjan Plain subsidence, one parameter out of five input parameters was put aside each time and the remaining four parameters were used to train the network. The obtained simulated model was then compared to the base model trained using all five parameters. This algorithm was repeated for all five input parameters. Ultimately, the model with the highest deviation from the base model was determined and the corresponding omitted parameter was identified as the most influential one. It should be noted that the initializations at every training process were kept constant. This was done to ensure that the changes occurring on the network weights were merely due to the elimination of one of the five parameters and nothing else. For the quantitative evaluation of the results, as described in Sec. 3.1, the residual map was produced via subtracting the subsidence rates map estimated using only four parameters from the base model. The results are shown in Figs. 17-21, and the RMSE values were calculated (Table 3). According to the results depicted 
(a)

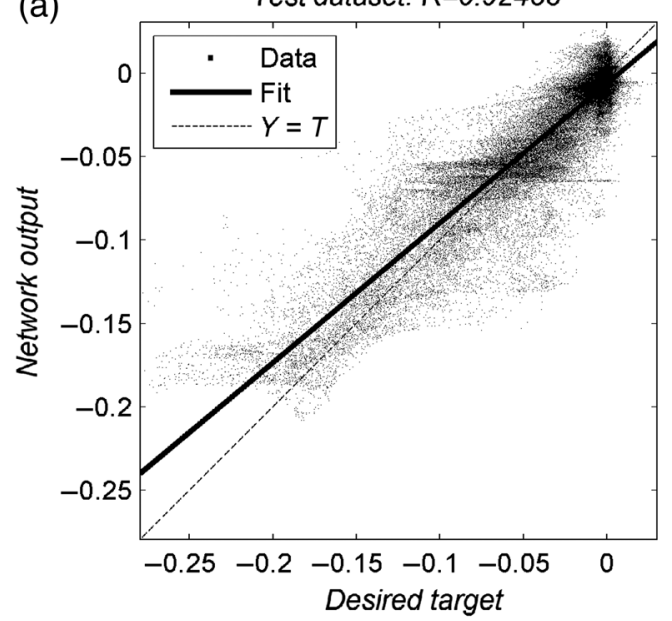

(b)

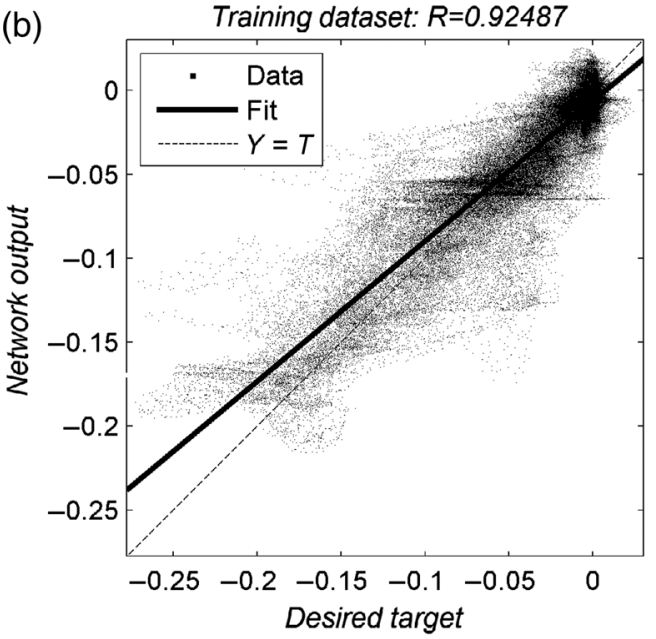

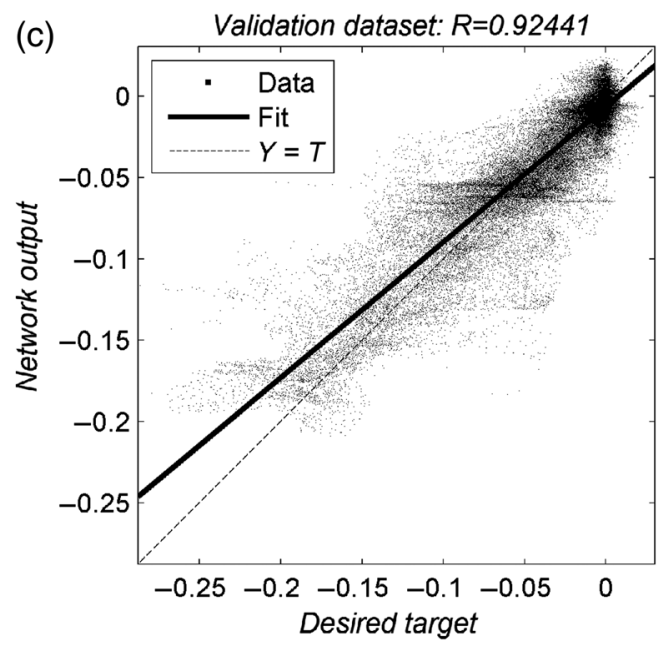

Fig. 16 Diagrams of the network outputs versus the desired targets and regression lines: (a) test dataset, (b) training dataset, and (c) validation dataset.

Table 2 Regression equations fitted to the network outputs versus the desired targets.

\begin{tabular}{lcc}
\hline \hline Data & Regression equations & Correlation $(R)$ \\
\hline Test & $0.85 T+0.0058$ & 0.92488 \\
Training & $0.86 T+0.0056$ & 0.92487 \\
Validation & $0.85 T+0.0057$ & 0.92441 \\
\hline \hline
\end{tabular}

in Figs. 17 and 18 and Table 3, the simulated models without both average groundwater level depth and groundwater level decline layer have highest deviation from the base model especially in areas where land subsidence occurred with respect to other areas (areas without any subsidence). This means that there is a significant relationship between these parameters and land subsidence. The close RMSE calculated for each of these two layers in Table 3 indicate the same issue. Therefore, ANN approach without the presence of these parameters led to wrong conclusions. After these two parameters, the lack of geological parameters has shown the greatest impact on the assessment of land subsidence. Coarse-grained materials, such as sand and gravel, transmit water readily, whereas fine-grained materials, such as clay and silt, 


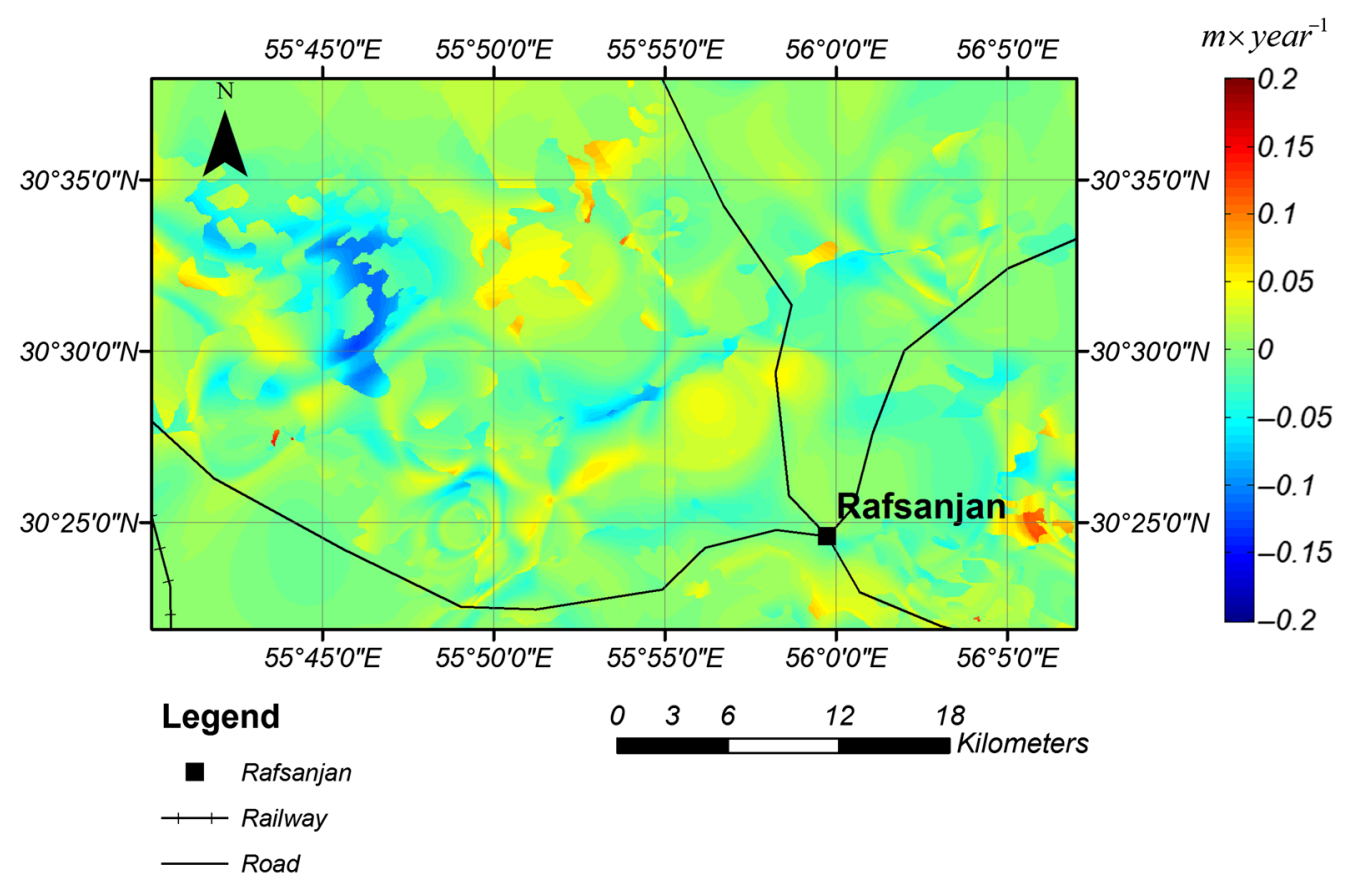

Fig. 17 Residual maps yield from sensitivity analysis process. Parameter is removed: average groundwater level depth.

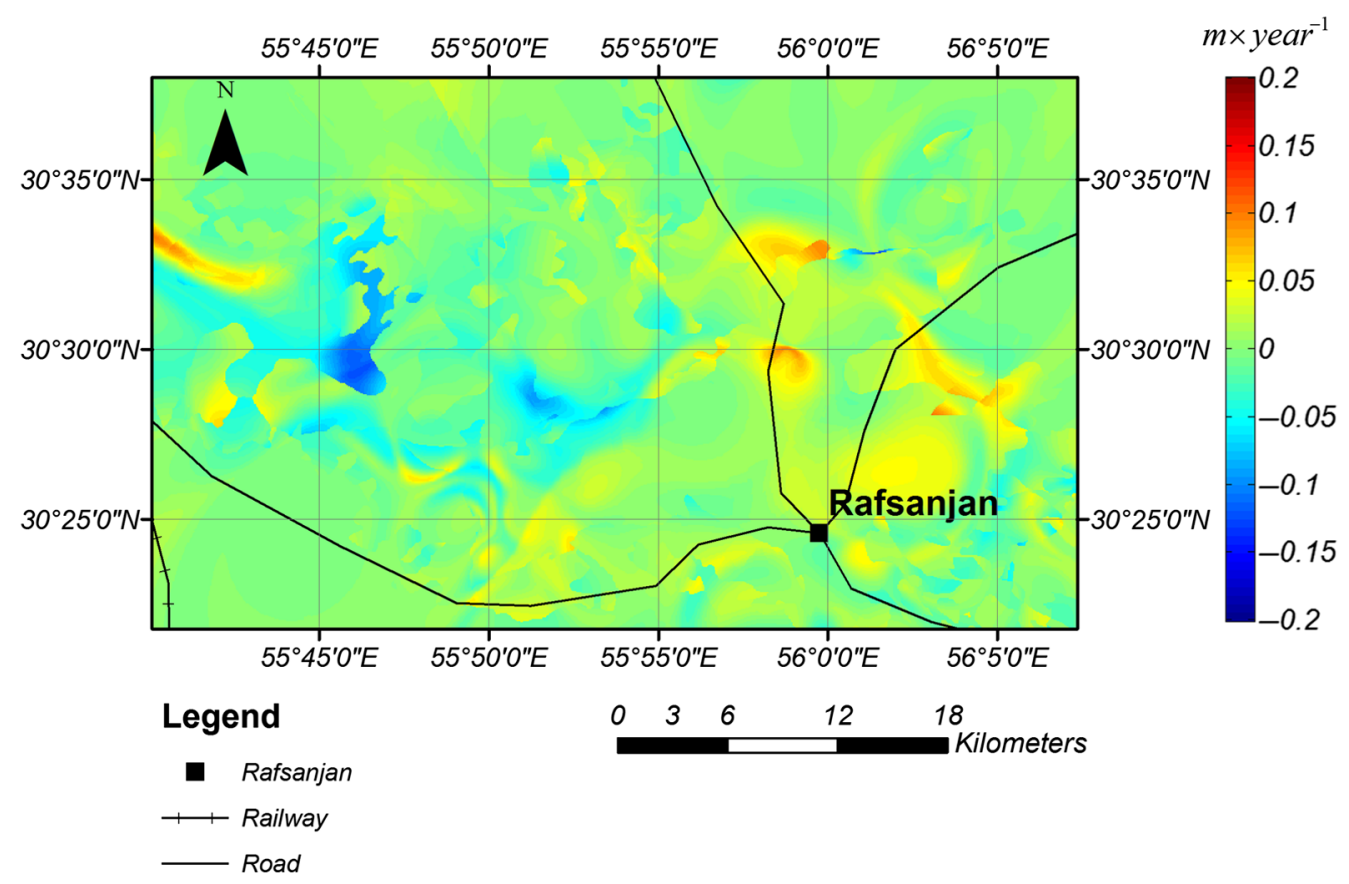

Fig. 18 Residual maps yield from sensitivity analysis process. Parameter is removed: groundwater level decline.

impede the movement of water. In particular, when water is drained from clays, permanent subsidence will result because much of the water drained cannot be replaced. As shown in Fig. 7, soil type of the most of the subsidence areas are silt and clay. Therefore, it can be concluded that the geology parameter can be one of the important parameters for assessment of land subsidence using ANN. 


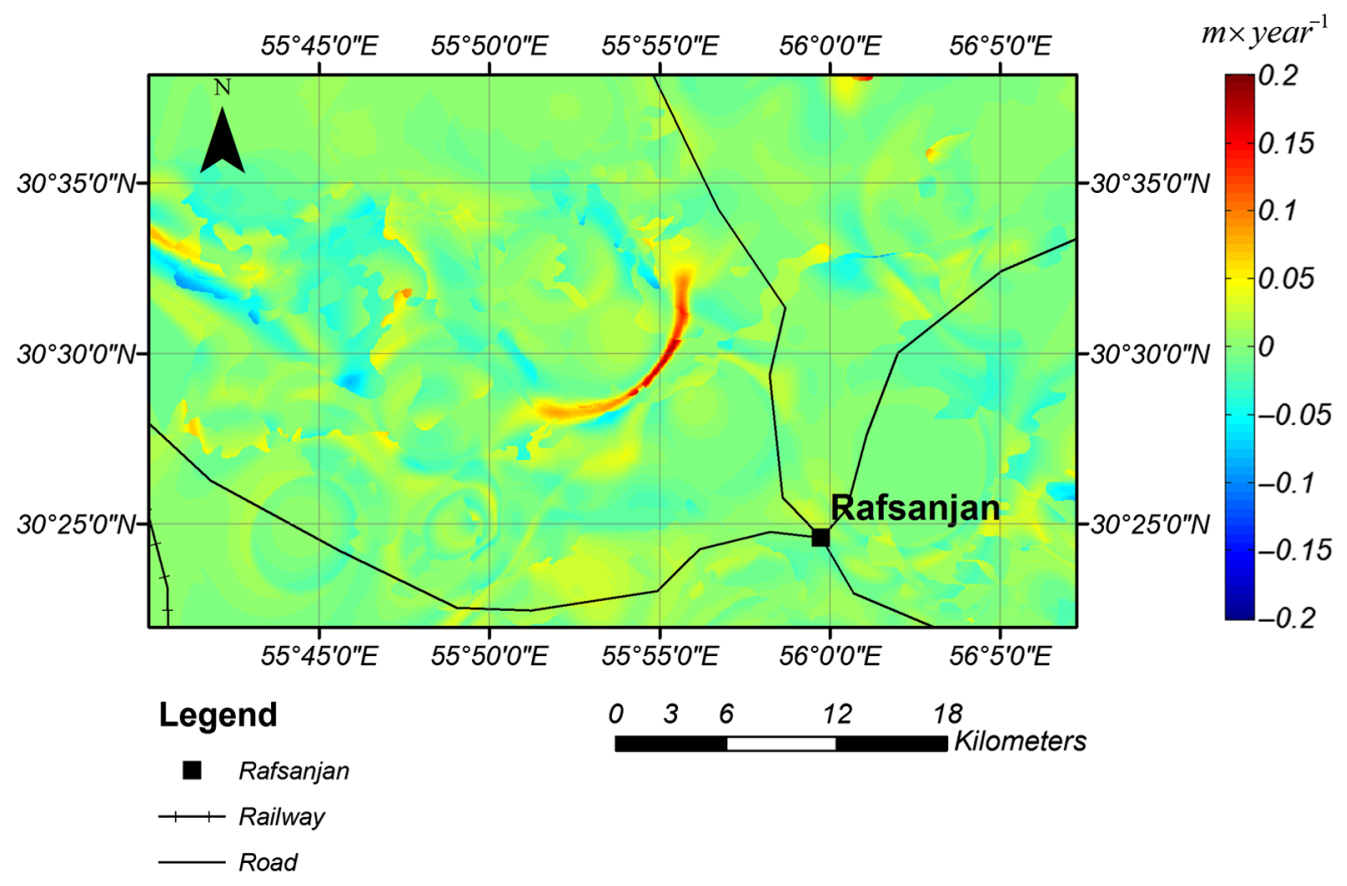

Fig. 19 Residual maps yield from sensitivity analysis process. Parameter is removed: geology.

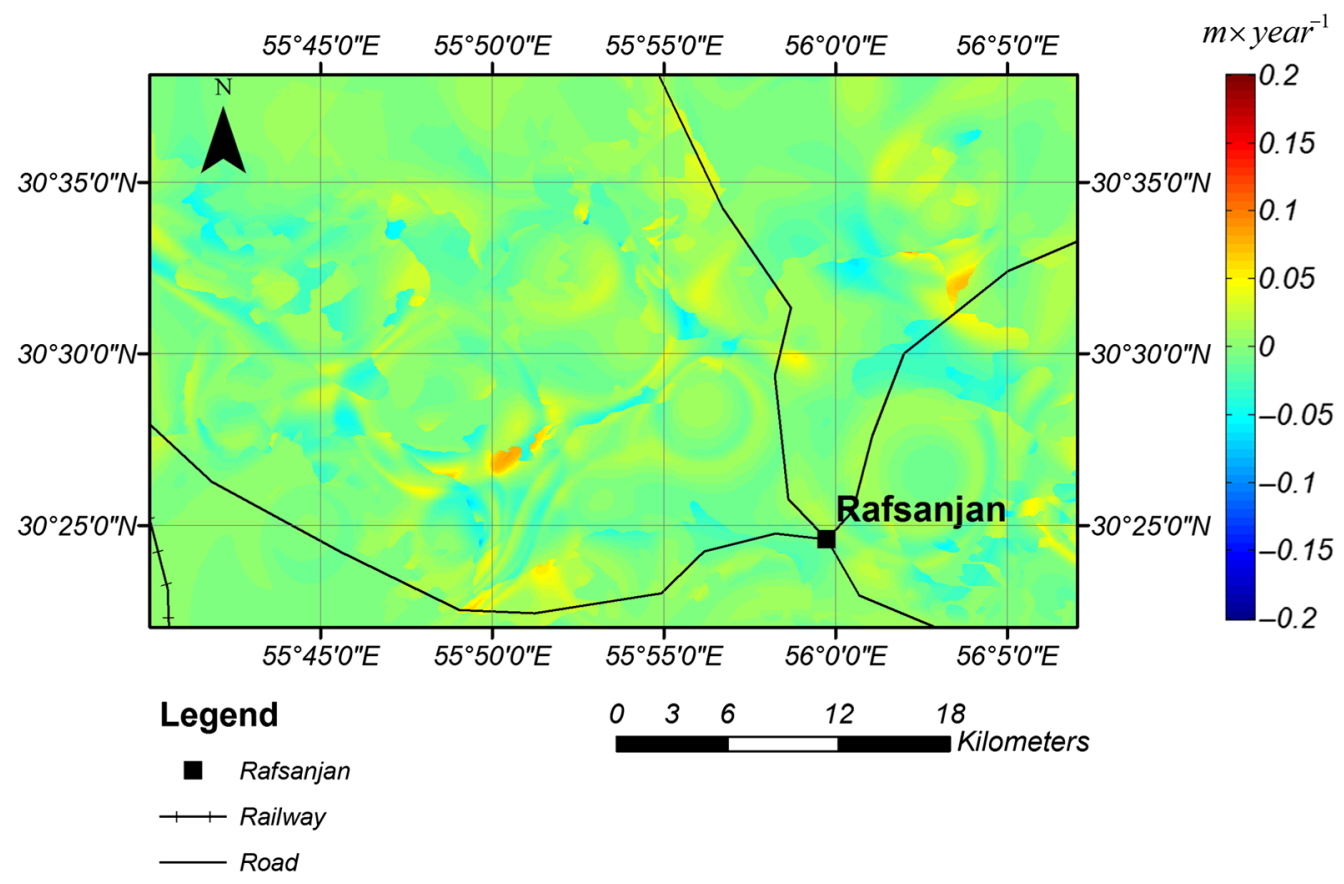

Fig. 20 Residual maps yield from sensitivity analysis process. Parameter is removed: hydraulic transmissivity.

\section{Conclusions}

As observed from the residual map, the most significant part of the subsidence was modeled by the neural network. The RMSE of $0.0183 \mathrm{~m} \times$ year $^{-1}$ estimated from the residual map indicated the high accuracy of the model. The histogram of the model error represented the concentration of the errors around zero. The correlation between the network outputs and the InSAR-derived deformation rate was estimated as 0.92 for all training, test, and validation datasets. The high correlation indicates that the ANN could approximate the land subsidence that occurs in a nonlinear relationship with the factors affecting it. According to the results of the sensitivity analysis, 


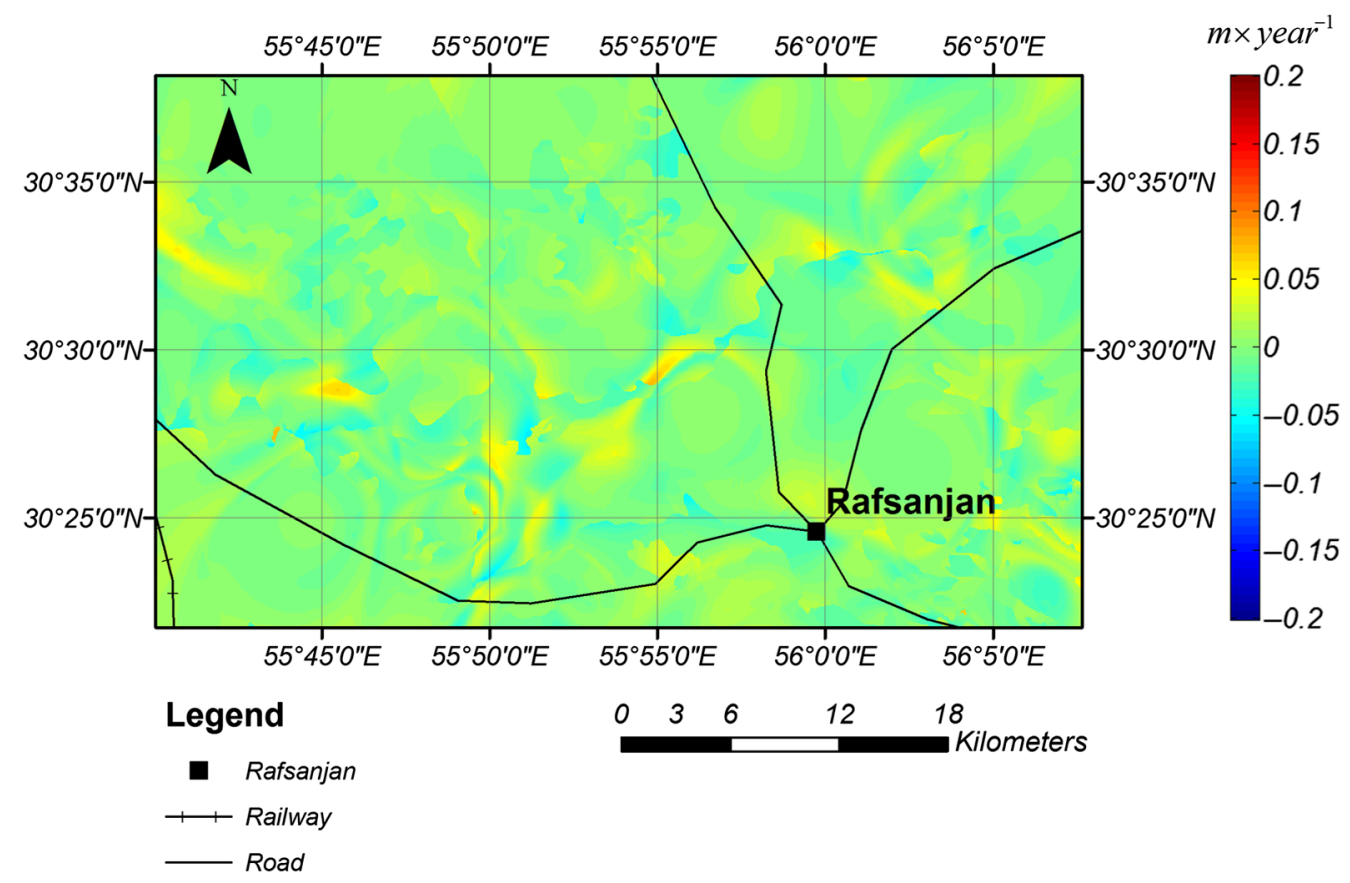

Fig. 21 Residual maps yield from sensitivity analysis process. Parameter is removed: land use.

Table 3 RMSE calculated for the results obtained from the model with four parameters and the base model.

\begin{tabular}{lc}
\hline \hline Removed layer & RMSE $\left(\mathrm{m} \times\right.$ year $\left.^{-1}\right)$ \\
\hline Average groundwater level depth & 0.0215 \\
Groundwater level decline & 0.0208 \\
Geology & 0.0154 \\
Hydraulic transmissivity & 0.0130 \\
Land use & 0.0123 \\
\hline \hline
\end{tabular}

average groundwater level depth and groundwater level decline were determined to be the parameters with the greatest impact on the assessment of land subsidence using ANN as expected. The geology was determined as the next most effective parameters. Therefore, it can be concluded that a large portion of land subsidence can be modeled using these three parameters. Adding further hydrogeological information such as storage coefficient, hydraulic conductivity, and percentage of fine-grained sediments within the aquifer system would improve the modeling results. The results of the validation and sensitivity analysis stages also revealed that the ANN approach can be used as a complementary for InSAR method to estimate the land subsidence. It should be noted that due to the lack of GPS and leveling measurements in the study area, the only criterion for evaluation of the results obtained from ANN is both test and validation datasets, which contain high-quality measurements of InSAR. The subsidence rates estimated from the trained ANN agree well with those measured by InSAR. Hence, modeling based on ANN method has the ability to estimate the deformation rate in those areas in which measuring the subsidence was not feasible using InSAR.

\section{Acknowledgments}

The authors would like to thank the European Space Agency and the Kerman Regional Water Organization for providing the ENVISAT ASAR data and hydrogeological information, 
Bagheri et al.: Assessment of land subsidence using interferometric synthetic aperture radar...

respectively. All authors designed the algorithm, processed and validated the data and wrote paper. The authors declare no conflict of interest.

\section{References}

1. M. A. Biot, "General theory of three-dimensional consolidation," J. Appl. Phys. 12, 155-164 (1941).

2. A. Nikdel, Overview of the Motion Mechanism and Land Subsidence Caused by Tectonic Motions and Groundwater Exploitation in Rafsanjan Plain, Regional Water Organization, Kerman (1992).

3. P. Bonder and E. D. Rouffignac, "Land subsidence and well failure in the Belridge diamomite oil field, Kern County, California," in Proc. Fifth Int. Symp. Land Subsidence, pp. 69-78 (1995).

4. T. Q. Naguyen and D. C. Helm, "Land subsidence due to groundwater withdrawal in Hanoi, Vietnam,” in Proc. Fifth Int. Symp. Land Subsidence, pp. 55-60 (1995).

5. W. Bertoni et al., "Land subsidence due to gas production in the on-and-off-shore natural gas fields of the Ravenna area, Italy," in Proc. Fifth Int. Symp. Land Subsidence, pp. 13-20 (1995).

6. M. Khamehchiyan, Study on Geotechnical and Geoenvironmental Aspects of Land Subsidence due to Withdrawal of Groundwater, Saga University, Saga, Japan (1995).

7. D. L. Galloway and F. S. Riley, "San Joaquin Valley, California-largest human alteration of the earth's surface," U.S. Geol. Surv. Circ., D. L. Galloway, D. R. Jones, and D. L. Ingebritsen, pp. 23-34 (1999).

8. S. M. Mousavi, Analysis of Interactions of Hydraulic Parameters and Land Subsidence Due to Groundwater Extraction, Sharif University, Tehran (1999).

9. P. Teatini et al., "Resolving land subsidence within the Venice Lagoon by persistent scatterer SAR interferometry," Phys. Chem. Earth Parts A/B/C 40-41, 72-79 (2010).

10. G. Herrera et al., "Forensic analysis of buildings affected by mining subsidence based on differential interferometry (part III)," Eng. Fail. Anal. 24, 67-76 (2012).

11. D. L. Galloway, D. R. Jones, and S. E. Ingebritsen, "Land subsidence in the United States," U.S. Geol. Surv. Circ. 1182, 177p (1999).

12. H. H. Schumann and J. F. Poland, "Land subsidence, earth fissures, and groundwater withdrawal in South Central Arizona, U.S.A,” in Int. Symp. Subsidence, pp. 295-302 (1969).

13. T. L. Holzer, "Reconnaissance maps of earth fissures and land subsidence, Bowie and Willcox areas, Arizona," in U.S. Geological Survey Miscellaneous Field Studies Map, MF-1156, 2 sheets, scale 1:24,000, Northern Sulphur Springs Valley, San Simon Valley (1980).

14. W. E. Strange, "Subsidence Monitoring for the State of Arizona," National Oceanic and Atmospheric Administration Report, p. 74, U.S. Department of Commerce, Washington D.C. (1983).

15. H. H. Schumann and L. S. Cripe, "Land subsidence and earth fissures caused by groundwater depletion in Southern Arizona, U.S.A," in Proc. 3rd Int. Symp. Land Subsidence, Venice, International Association of Hydrological Science Press, Wallingford, pp. 841851 (1986).

16. A. Choopani, M. Dehghani, and M. R. Nikoo, "Determining hydrogeological parameters of an aquifer in Sirjan Basin using Envisat ASAR interferometry and groundwater modelling," Int. J. Remote Sens. 41(2), 655-682 (2019).

17. K.-D. Kim, S. Saro Lee, and H.-J. Oh, "Prediction of ground subsidence in Samcheok City, Korea using artificial neural networks and GIS," Environ. Geol. 58(1), 61-70 (2009).

18. S. M. VaeziNejad, M. M. Toufigh, and S. M. Marandi, "Zonation and prediction of land subsidence (case study-Kerman, Iran)," Int. J. Geosci. 2(2), 102-110 (2011).

19. D. Massonnet and K. L. Feigl, "Radar interferometry and its application to changes in the earth's surface," Rev. Geophys. 36(4), 441-500 (1998).

20. M. Dehghani, M. J. V. Zoej, and I. E. Soltani, "Neural network modelling of Tehran land subsidence measured by persistent scatterer interferometry," Photogramm. Fernerkundung Geoinf. 2013, 5-17 (2013). 
Bagheri et al.: Assessment of land subsidence using interferometric synthetic aperture radar...

21. R. T. Walker and M. Fattahi, "A framework of Holocene and Late Pleistocene environmental change in eastern Iran inferred from the dating of periods of alluvial fan abandonment, river terracing, and lake deposition," Quat. Sci. Rev. 30(9-10), 1256-1271 (2011).

22. S. N. Sivanandam and S. N. Deepa, Introduction to Neural Networks Using Matlab 6.0, Tata McGraw-Hill Education, New Delhi, India (2006).

23. S. Haykin, Neural Networks: A Comprehensive Foundation, 2nd ed., Prentice Hall PTR, Upper Saddle River, New Jersey (1998).

24. R. Bürgmann, P. A. Rosen, and E. J. Fielding, "Synthetic aperture radar interferometry to measure earth's surface topography and its deformation," Annu. Rev. Earth Planet. Sci. 28, 169-209 (2000).

25. R. F. Hanssen, Radar Interferometry: Data Interpretation and Error Analysis, 1st ed., Springer Science \& Business Media, Dordrecht, Netherlands (2001).

26. M. Dehghani et al., "InSAR monitoring of progressive land subsidence in Neyshabour, northeast Iran," Geophys. J. Int. 178, 47-56 (2009).

27. J. A. Reeves et al., "High quality InSAR data linked to seasonal change in hydraulic head for an agricultural area in the San Luis Valley, Colorado," Water Resour. Res. 47(12) (2011).

28. D. W. Marquardt, "An algorithm for least-squares estimation of nonlinear parameters," J. Soc. Ind. Appl. Math. 11(2), 431-441 (1963).

29. K. Levenberg, "A method for the solution of certain non-linear problems in least squares," Q. J. Appl. Math. 2(2), 164-168 (1944).

30. B. M. Damghani et al., "The misleading value of measured correlation," Wilmott 2012, 64-73 (2012).

31. K. Pearson, "Note on regression and inheritance in the case of two parents," Proc. R. Soc. Lond. 58, 240-242 (1895).

32. S. M. Stigler, "Francis Galton's account of the invention of correlation," Stat. Sci. 4, 73-79 (1989).

33. S. Hashem, "Sensitivity analysis for feedforward artificial neural networks with differentiable activation functions," in Int. Joint Conf. Neural Networks, IEEE, Baltimore, Maryland, pp. 419-424 (1992).

34. C. C. Klimasauskas, "Neural nets tell why," Dr. Dobbs's J. 16(4), 16-24 (1991).

Mohsen Bagheri received his MS in geospatial information system (GIS) from Graduate University of Advanced Technology, Kerman, Iran, in 2013. His main research interests include synthetic aperture radar (SAR) interferometry, spatial hazard mapping using GIS, and artificial intelligence.

Maryam Dehghani received her BS degree in geodesy and geomatics engineering from Iran University of Science and Technology, Iran, and her MSc degree and $\mathrm{PhD}$ in remote sensing from K. N. Toosi University of Technology, Iran, in 2004 and 2009, respectively. Currently, she is an associate professor in the Department of Civil and Environmental Engineering, School of Engineering, Shiraz University, Shiraz, Iran. Her main research interests include SAR interferometry and digital image processing.

Ali Esmaeily received his BS degree in geodesy and geomatics engineering from K. N. Toosi University of Technology, Iran, in 1989, his MSc degree from the University of Quebec, Canada, in 1996, and his PhD from the University of Sherbrooke, Canada, in 2008. Currently, he is the head of GIS and Remote Sensing Department of Graduate University of Advanced Technology, Kerman, Iran. His main research interests include SAR interferometry and digital image processing.

Vahid Akbari received his $\mathrm{PhD}$ in physics major in earth observation from the UiT, the Arctic University of Norway, Tromsø, Norway, in 2013. Currently, he is a research scientist in earth observation at Division of Forest and Forest Resources of Norwegian Institute of Bioeconomy Research. His research interests is mainly on the use of interferometric and polarimetric SAR from satellite, and aircraft sensors for studies of land deformation, land cover classification, and change detection, as well as marine target detection and characterization in polar regions. 